\title{
PROCESIONES Y RELIGIÓN CÍVICA EN ZARAGOZA. LOS PREGONES DEL CONCEJO ENTRE 1450 Y 1500
}

\author{
PROCESSIONS AND CIVIC RELIGION IN ZARAGOZA: \\ THE COUNCIL PROCLAMATIONS BETWEEN 1450 AND 1500
}

\author{
Inmaculada MELÓN JUNCOSA \\ Universidad de Zaragoza
}

\begin{abstract}
Resumen: El Archivo Municipal de Zaragoza conserva gran número de pregones entre 1450 y 1500. En muchos de ellos, los jurados de la ciudad convocan a los zaragozanos a participar en distintas procesiones religiosas. Su lectura permite confeccionar una tipología procesional, estudiar las devociones más comunes, describir las rutas procesionales habituales y analizar el papel de las autoridades civiles en un fenómeno típicamente religioso para concluir si podría hablarse de religión cívica en la Zaragoza de la segunda mitad del siglo Xv.
\end{abstract}

Palabras clave: religión cívica, procesiones, pregones, Zaragoza, siglo $\mathrm{XV}$, 1450-1500.

\begin{abstract}
The Municipal Archives in Zaragoza keep a large number of proclamations between 1450 and 1500. In many of these, the aldermen summon the inhabitants to participate in various religious processions. Through detailed reading, it is possible to make a processional typology, to study the most common devotions, to describe processional routes and to analyse the role of the civil authorities in these religious events to conclude whether it might be possible to speak of civil religion in Zaragoza in the second half of the $15^{\text {th }}$ century.
\end{abstract}

Key words: civic religion, processions, proclamations, Zaragoza, $15^{\text {th }}$ century, 1450-1500. 


\section{Introducción}

El estudio de las procesiones presenta múltiples facetas, desde las puramente devocionales y rituales hasta las económicas, culturales, identitarias y simbólicas. Los historiadores se han acercado a él desde la especificidad del dogma cristiano y desde la universalidad de los referentes antropológicos, pero también con la visión cercana y diferenciadora de los estudios locales en las distintas ciudades europeas. Desde las obras de Vauchez y Chiffoleau de los años 80 y 90 del siglo xx sobre la espiritualidad y la religión cívica, se han multiplicado los estudios sobre procesiones y otro tipo de rituales para ciudades como París, Tours, Angers, Brujas, Bolonia, etc. También la ciudad de Zaragoza ha sido objeto de atención por parte de historiadores e historiadoras del ámbito de la Corona de Aragón. Este artículo pretende enraizarse dentro de esta corriente y seguir la estela de trabajos como los de Falcón Pérez, Mateos Royo, Rodrigo Estevan, Narbona Vizcaíno, Serrano Martín, Buesa Conde, Del Campo Gutierrez, Tello Hernández y Jean Pierre Barraqué entre otros. ${ }^{1}$

Se pretende realizar un análisis de las procesiones religiosas en la Zaragoza de la segunda mitad del siglo XV utilizando para ello la información que proporcionan al respecto los Libros de Pregones. ${ }^{2}$ Para este estudio se han seleccionado los 132 pregones de convocatoria de procesiones emitidos en la ciudad entre 1450 y 1500 por orden de los jurados de Zaragoza. Estos pregones que se han conservado no sólo proporcionaron información imprescindible a los zaragozanos en su día a día, sino que contenían cláusulas prohibitivas, mandatos o incluso sanciones para los que contraviniesen las órdenes municipales. Convenía, pues, hacerlos llegar a todos los rincones de la ciudad y

1 Este autor analiza en dos artículos de 2008 y 2013 que aparecen citados en la bibliografía dos series de ritos en la Zaragoza bajomedieval: los relacionados con la persona del rey y los que giran alrededor de los patronos de la ciudad. Para Barraqué, la vocación de Zaragoza como capital del Reino habría causado el fracaso de la construcción de una religión cívica en la baja Edad Media.

2 El Archivo Municipal de Zaragoza conserva un fondo de 17 Libros de Pregones o Cridas, correspondientes a los siglos XV, XVI y XVII, que habían de ser leídos en los lugares públicos. Los asuntos tratados son diversos: urbanismo, control ciudadano, celebraciones religiosas, abastos, etc. No se dispone de cridas para todos los años del periodo y la cantidad de pregones por año es irregular. La siguiente relación muestra la distribución de los pregones en los distintos libros y cuadernillos, sistema que se seguirá al hacer mención de los mismos durante este artículo:

ES. 50297. AM 01.05.03 Libro Signatura PRE-01: años 1486, 1488, 1483 y 1482.

- $\quad$ ES. 50297. AM 01.05.03 Libro Signatura PRE-02: años 1450, 1452, 1454, 1455, 1459, 1462, $1465,1466,1468,1469,1470,1472,1474$ y 1476 a 1480.

- $\quad$ ES. 50297. AM 01.05.03 Libro Signatura PRE-03: año 1481.

- $\quad$ ES. 50297. AM 01.05.03 Libro Signatura PRE-04: años 1499 y 1500. 
no es difícil imaginar que los pregoneros al servicio del Concejo gritaron sus pregones no sólo desde la propia sede del gobierno municipal sino desde de múltiples ubicaciones. Estos lugares fueron conocidos por todos —razón por la que no se considera necesario mencionarlos en el propio pregón- y los moradores de la urbe acudían a ellos con regularidad para ponerse al corriente de las disposiciones de los munícipes.

De esta forma, y estudiando la relación de las procesiones con los poderes locales tanto por lo que respecta a la organización como al simbolismo que supone el control del espacio urbano, se busca concluir si es posible aplicar el concepto de religión cívica postulado por Vauchez (1995: 1): «l'ensemble des phénomènes religieux — cultuels, dévotionnels ou institutionnels - dans lesquels le pouvoir civil joue un rôle déterminant, principalement à travers l'action des autorités locales et municipales.»

En el centro de esta definición se encuentra el problema de la apropiación de los valores religiosos por los poderes civiles locales que son, en determinado momento, lo suficientemente fuertes como para tomar la iniciativa en este ámbito sin encontrar excesiva resistencia u oposición de las autoridades eclesiásticas. Para este autor (Vauchez, 1995: 2) es posible hablar de religión cívica cuando la comunidad civil se arroga prerrogativas más o menos extensas en el campo religioso, como por ejemplo la gestión de donativos para la construcción de edificios religiosos, la gestión económica de los hospitales y las obras de caridad y un cierto control sobre las reliquias de los santos o la organización de las procesiones.

Este fenómeno, que se habría producido en los últimos siglos de la Edad Media, habría estado impulsado por distintos factores como la necesidad de las autoridades locales de estimular un sentimiento de unidad, identidad y paz social en un momento de tensión entre los grupos urbanos o la aspiración de las élites de controlar los asuntos de interés común y mantener su posición de privilegio.

El primer problema que el propio Vauchez encuentra es el peligro de asimilar la noción de religión cívica a un movimiento de secularización abierto o incluso larvado. Se trataría más bien de un proceso que llevaría aparejados dos objetivos. Por un lado, crear un vínculo sagrado entre la ciudad y las autoridades municipales a través del control de las prácticas religiosas; por otro, revestir a la autoridad civil de un carácter sagrado, de forma que se potenciara su legitimidad. En este control del fenómeno religioso no existiría necesa- 
riamente una rivalidad entre el poder civil y el religioso sino, más bien, un círculo de beneficio mutuo.

Como en todo tipo de religión, el papel de los ritos y ceremonias es también esencial en la religión cívica. El rito proporciona una experiencia vital $y$, en el caso de los ritos colectivos, la participación en él es valiosa para la totalidad del grupo. El rito y la celebración religiosa reflejan a la par que crean una cosmovisión a través de los símbolos. Para los que participan en las ceremonias, estas son «materializaciones, realizaciones, no solo de lo que creen, sino que son también modelos para creer en ello.» (Geertz, 2003: 108)

Las procesiones están íntimamente ligadas a las fiestas y constituyen, en muchas ocasiones, el rito principal. Podemos definirlas como desfiles religiosos en grupo que recorren un lugar como muestra de fe. En función de las ciudades y sus circunstancias, es posible trazar una tipología procesional, analizar las devociones y motivos procesionales y estudiar qué tipo de autoridad las origina. Por lo que respecta a su naturaleza, las procesiones son acontecimientos colectivos (al contrario que las peregrinaciones), lo que añade una dimensión social a su carácter litúrgico.

En una procesión general, el espacio que forma la ciudad juega un papel fundamental. Lo divino sale del templo a la calle, borrándose los límites entre el espacio sagrado y el profano. Las calles por las que pasa la procesión se colocan bajo la protección divina y se someten a las normas del espacio religioso. Simultáneamente, lo profano entra en lo sagrado, lo cual exige extremar el cuidado para que no haya riesgo de contaminación (Leone, 2014: 315-316).

A finales de la Edad Media, en algunas ciudades europeas comenzaron a formarse sistemas procesionales en los que se mezclaba liturgia, política y sociedad. En ellos, los motivos, la frecuencia y la autoridad de la que parte la organización de la procesión son factores primordiales para formular una tipología. Entre los motivos ocupan un lugar destacado la devoción al Cuerpo y Sangre de Cristo y a la Virgen y la veneración a los santos patronos de la ciudad - tendencia que se intensificó a finales de la Edad Media. Aunque las ciudades podían tener un patrón principal, muchas de ellas contaron también con una cohorte de santos protectores. Las razones para elegir un santo patrón fueron múltiples, pero una de las determinantes fue la presencia en la ciudad de las reliquias del santo, que tanto la ciudad como la iglesia en la que se custodiaban intentaban promocionar. 


\section{Las procesiones en la Zaragoza de la segunda mitad del siglo XV}

El gran número de cridas de procesión presentes en los Libros de Pregones apunta al papel que jugaron estas ceremonias religiosas tanto para las autoridades municipales como para toda la sociedad civil zaragozana de la Baja Edad Media. En especial, las procesiones solemnes significaban para los munícipes la ocasión de hacer visible su autoridad a través de la organización y gestión de las mismas; para los vecinos, su implicación en la res publica y su colaboración con el bien común; para Zaragoza en general, la ocasión de mostrar su importancia y su identidad como ciudad.

La documentación presenta gran irregularidad en la cadencia anual de las procesiones zaragozanas. Es de suponer que parte de los pregones se hayan perdido con el paso del tiempo, pero no deja de sorprender el hecho de que, en años cercanos, el número de llamamientos a los vecinos a participar en procesiones sea tan dispar. (Figura 1).

NÚMERO DE PROCESIONES ENTRE 1450 Y 1459

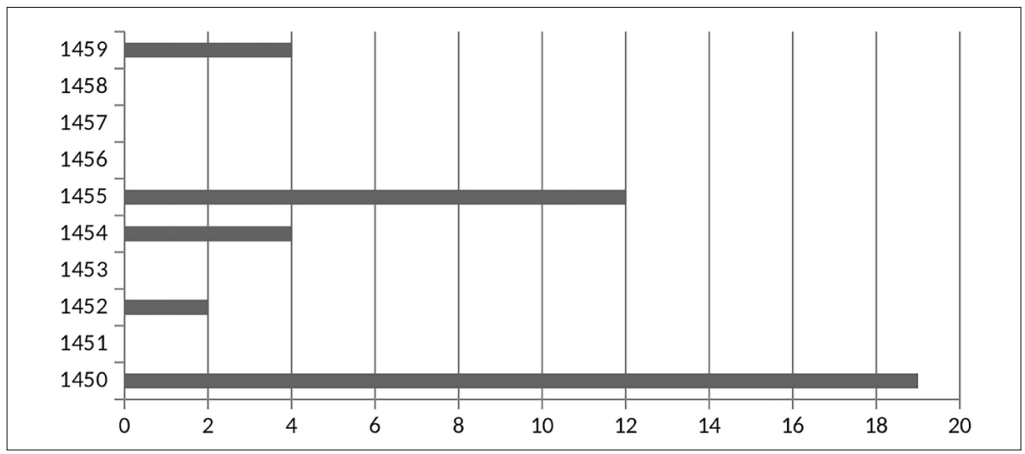

Figura 1. Llamamientos a procesiones zaragozanas entre 1450 y 1459 según los Libros de Cridas. (Elaboración propia).

En cuanto a la tipología procesional, conviene, en primer lugar, diferenciar entre lo que constituiría un ciclo procesional regular y las circunstancias que llevarían a las autoridades a recabar la participación ciudadana en momentos específicos. Atendiendo a la periodicidad, es posible clasificar las procesiones en la ciudad de Zaragoza en dos grupos:

a) Procesiones ordinarias o regulares. Aparecen en la documentación casi todos los años o los pregones las califican de procesiones acostumbradas; son utilizadas por las autoridades para crear una identidad urbana. 
b) Procesiones ocasionales o extraordinarias. No se ajustan a un calendario sino a condiciones excepcionales en la ciudad o el reino y muestran claramente las preocupaciones de la ciudad en coyunturas específicas (guerras, pestes, etc.).

\subsection{Procesiones ordinarias o regulares}

Seleccionando las procesiones de carácter ordinario a las que aluden los pregones, es posible establecer un calendario - teniendo en cuenta la presencia de algunas variantes - a lo largo del periodo 1450-1500:

— 20 de enero: san Fabián y san Sebastián.

- 12 de marzo: san Gregorio (en la década de los 50 del siglo xv).

- Antes del 18 de marzo: san Braulio (solo existe la crida de 1452 anterior al mes de mayo).

— 25 de marzo: Encarnación de la Virgen María.

- 16 de abril: santa Engracia.

- 23 de abril: san Jorge, desde 1461.

- Primer domingo de mayo: santa Catalina de Siena (solo existe la crida de 1465 en la que se ordena que se celebre su fiesta cada año).

- Corpus Christi (fecha móvil).

- 19 de junio: san Gregorio y san Lamberto desde 1481. Entre 1459 y 1481 la festividad de San Gregorio cambia de marzo a los alrededores del día 20 de junio.

- Julio, primer domingo siguiente a la octava de san Pedro y san Pablo (29 de junio) desde 1493 (Llompart, 1988: 250): Ángel Custodio. En los años 50 del siglo XV los pregones anuncian la fiesta entre los meses de mayo y junio. En 1481, la crida de la fiesta de san Gregorio y san Lamberto menciona la coincidencia, hasta ese año, de la fiesta del Ángel Custodio y la de san Lamberto (19 de junio).

- 3 de noviembre: santos Mártires.

- 8 de diciembre: Concepción de la Virgen María.

-28 de diciembre / 8 de enero: santos Inocentes.

En función de la devoción a la que atienden, podemos dibujar cuatro grandes grupos procesionales y analizar su vinculación con las autoridades civiles, tanto municipales como reales. 


\subsubsection{Las devociones cristológicas}

Las dos festividades de carácter cristológico en la Zaragoza de finales del siglo Xv son el martes de Pascua de Resurrección y el Corpus Christi, ${ }^{3}$ ambas ligadas a la identidad de la ciudad.

Con motivo de la primera, se celebraba una procesión ordinaria al Hospital de Gracia ${ }^{4}$ de la que nos ha quedado constancia en dos pregones de $1465^{5} \mathrm{y}$ 1486. ${ }^{6}$ Esta procesión del martes de Pascua podría estar en relación con la elección de cargos mayores y menores del Hospital que, como menciona Falcón Pérez (1980: 194) tenía lugar el primer miércoles después del domingo de Resurrección, es decir, al día siguiente.

Por lo que se refiere a la celebración del Corpus Christi en la capital aragonesa, las primeras noticias se remontan a $1423 \mathrm{y}$, en el periodo estudiado, se detecta una creciente implicación del Concejo en su organización y control. En estos cincuenta años contamos con quince pregones de Corpus Christi, ${ }^{7}$ cada vez más elaborados y prolijos en detalles. A medida que pasan los años aparecen en ellos elementos nuevos — como la utilización de candelas, carrozas para los entremeses o múltiples prohibiciones a los vecinos y, en especial, a las minorías religiosas - que tienden a perpetuarse en la liturgia procesional construyendo un evento progresivamente más complejo y festivo. Es precisamente este creciente carácter lúdico y sus excesos lo que lleva a las autoridades a extremar, con el paso del tiempo, las medidas de orden público y el decoro debido al sacramento, manifestándose también de este modo una mayor implicación del poder civil en la celebración. Así, si bien en $1450^{8}$ el Concejo solo prohíbe, bajo pena de 5 sueldos, ir a caballo por donde transite

3 Fiesta móvil establecida por bula del papa Urbano IV en 1264. Constituye la principal celebración cívico-religiosa medieval ya que, en ella, el desfile jerarquizado de la sociedad reflejaba el corpus mysticum de la comunidad cristiana. Para el caso de Zaragoza, ver los trabajos de Isabel Falcón Pérez. Institución creada en 1425 a instancias de las autoridades municipales. Estuvo desde sus primeros momentos regido por el concejo y el cabildo de la Seo y contó con la protección real. Para conocer su organización, puede consultarse el artículo de Cristina Monterde Albiac (2008), «Las Ordinaciones del Hospital de Nuestra Señora de Gracia de Zaragoza establecidas por Don Alfonso de Aragón, arzobispo de Zaragoza y lugarteniente general del Reino», Aragón en la Edad Media, 20: 505-528.

5 PRE-02, cuadernillo 7, ff. 12r. y v.

6 PRE-01, cuadernillo 1, ff. 10v. y 11r.

7 Ángel San Vicente transcribe algunos de estos pregones en Instrumentos para una historia social y económica del trabajo en Zaragoza en los siglos XV a XVIII, al igual que Isabel Falcón en los dos artículos de 1982 que aparecen en la bibliografía. También es posible encontrar fragmentos transcritos de los pregones del Corpus Christi en el artículo de José Antonio Mateos (2001).

8 PRE-02, cuadernillo 1, f.17r 
la procesión, a partir del año $1472^{9}$ tal infracción supondría la pérdida de la cabalgadura a beneficio de la ciudad; en $1455^{10}$ se prohíben caretas, juegos y cohetes bajo pena de cárcel; en $1459^{11}$ la prohibición se amplía a los entremeses de carácter deshonesto y los disfraces de diablo (a no ser que el individuo vaya en el entremés del infierno) y en $1474^{12}$ se decretan penas de azotes para los que osen disfrazarse de fraile o capellán.

Los dramas religiosos vinculados en buena parte con esta fiesta y conocidos como entremeses están relacionados con el modelo de evangelización promovido por las órdenes mendicantes. Al ser realizados a modo de teatro ambulante, en calles y plazas y sobre carros decorados, era imprescindible la colaboración de las autoridades civiles que debían organizar el espacio y el momento en el que tendrían lugar, hacer compatible estos dramas con la actividad diaria de la ciudad y garantizar el orden público durante los mismos. Los entremeses del Corpus de Zaragoza aparecen citados por primera vez en los pregones en 1459:

\footnotetext{
Item mandan los ditos jurados que qualquier persona que hira en los entremeses que en la dita fiesta se faran o por la carrera por do la dita procession ha de passar que yra cubierto de caraça o con habito de diablo que no pueda hir en la dita procession ni por la dita carrera sino que vayan ensemble et en la companya de aquellos qui fazen el entremes del infierno. ${ }^{13}$
}

Permitir que las personas circularan disfrazadas por las calles atentaba contra el decoro de la fiesta, pervirtiendo el sentido religioso del drama y potenciando el elemento lúdico. Además, los disfraces y caretas trastocaban el orden social y perturbaban la tranquilidad de las calles, motivo por el que las autoridades eran especialmente estrictas sobre el dónde y cuándo estaban tolerados. Era necesario regular el espacio en el que tendrían lugar los entremeses por dos motivos fundamentales: primero, por el riesgo, comentado anteriormente, de borrar los límites entre el espacio sagrado y el profano; segundo, por la propia logística del evento, ya que concentrar los actos permitía un control y una organización más sencilla a las autoridades. Por eso, en Zaragoza, la celebración de entremeses se regulaba en tiempo y espacio, variando según

9 PRE-02, cuadernillo 11. f. 17v.

10 PRE-02, cuadernillo 4, f.18r.

11 PRE-02, cuadernillo 5, ff. 14 r. y v.

12 PRE-02, cuadernillo 2, f. $14 \mathrm{v}$.

13 PRE-02, cuadernillo 5, ff.14rv. 
los años: en el Mercado, a las dos del mediodía (1459); ${ }^{14}$ en la plaza de la Diputación, el cap de la carrera, la casa de micer Guallat, el Mercado y delante de casa de micer Paulo (1472); ${ }^{15}$ en el Mercado después de comer (1476); ${ }^{16}$ en la plaza de la Seo primero y en el Mercado después de comer (1480). ${ }^{17}$

Esta última crida insiste en que la gente se abstuviese de celebrar entremeses en otros lugares bajo pena de severas multas. Sin embargo, en lo que parece una claudicación ante la evidencia de la popularidad de los entremeses y la dificultad de controlar el desbordamiento festivo, en 1488 una coletilla añade que «fecha la procession se puedan desfresar et fazer caraças et entremeses por alegria de la fiesta». ${ }^{18}$ Con el paso del tiempo, se incrementaron también las disposiciones que afectaban a la limpieza y decoración del espacio público, a las minorías étnico-religiosas y a la presencia en la procesión de las reliquias de los santos locales, aspectos que se analizarán más adelante.

\subsubsection{Las devociones marianas}

El 7 de diciembre de 1450 se registra la única mención a la Inmaculada Concepción, aunque la propia crida refiere la costumbre de celebrar la fiesta en el monasterio de San Francisco:

[...] como en la Santa Sinodo de Basilea ultimament celebrada se haya declarado dever seyer tenida por los fieles christianos la fiesta de la Conçepcion de la Virgen Maria la qual es cras martes e se celebrara su fiesta do se costumbra celebrar et festivar en el monesterio de Sant Ffrancisco de la dita ciudat $[\ldots]^{19}$

Recordemos aquí la defensa de este dogma por la comunidad franciscana y la influencia de esta orden en la Corona de Aragón. La ciudad asume esta influencia franciscana y se suma, con la comunidad de hermanos, a la fiesta de la Inmaculada Concepción — dogma decretado en el sínodo de Basilea de 1439, defendido desde Juan Duns Scoto por los franciscanos y combatido, entre otros, por los dominicos. La disolución del sínodo por el papa Eugenio IV dejó sin efecto todas las disposiciones, entre ellas el referido dogma que no

14 PRE-02, cuadernillo 5, f. 15r.

15 PRE-02, cuadernillo 11, f. 18 r.

16 PRE-02, cuadernillo 13, f. 21r.

17 PRE-02, cuadernillo 17, f. 13r.

18 PRE-01, cuadernillo 2, ff. 18rv.

19 PRE-02, cuadernillo 1, f. 35 r. 
sería definitivamente declarado por la Iglesia hasta la publicación de la bula Ineffabilis Deus de 1854.

En Zaragoza, esta fiesta se encontraba especialmente ligada al gobierno de la ciudad ya que desde 1333 la Inmaculada se convirtió en patrona de los oficiales municipales, agrupados bajo dicha advocación (Tello, 2013: 80). Desde que en 1414, Fernando I dotara a la ciudad de sus ordenanzas, la provisión de cargos municipales se celebró el día 7 (en ocasiones el 8) de diciembre; de esta forma, los fastos de la Inmaculada adquirían mayor solemnidad y se hacía posible contar con los nuevos cargos electos (Falcón, 2011b: 182). ${ }^{20}$ Un pregón de 1450 anunciaba a los zaragozanos la concesión de 140 días de indulgencia a todos los que acudieran a celebrar la fiesta. Animando de esta forma a la participación de los vecinos, los nuevos cargos municipales se garantizaban su visibilidad y reconocimiento en la ciudad. A pesar de ello, la mención a fiesta de la Inmaculada desaparece de los Libros de Pregones en fechas posteriores.

\subsubsection{Las devociones a santos y ángeles}

Permítaseme en este punto alterar el orden jerárquico y hablar primero de las devociones a santos y ángeles, por motivos de organización del discurso, para terminar en el siguiente apartado con los patronos y votos de la ciudad.

La mayor parte de las devociones a santos y ángeles están de uno u otro modo vinculadas con la ciudad o el reino del que es capital, quizá a excepción de la devoción a Santa Catalina de Siena y la devoción a los santos Fabián y Sebastián. La celebración de estos santos el 20 de enero parece responder a una devoción popular ya en marcha en 1450, año en el que se celebra una procesión al monasterio del Carmen. Recordemos que es este un año de peste y que san Sebastián estaba considerado como un santo protector ante este tipo de catástrofes. No en vano, a finales de la Edad Media había surgido un tipo de representación del santo similar al de las vírgenes de Misericordia en las que san Sebastián protegía de la peste a los fieles que buscaban cobijo bajo su manto. En 1455, y atendiendo a la devoción que la ciudad guarda a los santos, se decide convertir la fiesta en ordinaria y guardarla como el domingo:

20 Anteriormente, la renovación de los cargos municipales se realizaba el 15 de agosto, día de la Asunción de la Virgen. Así consta en las ordinaciones de 1311 y 1391. Ver Manuel Mora y Gaudó (ed.), Ordenanzas de la ciudad de Zaragoza, Zaragoza, Imprenta de Mariano Escar, 1908, vol. 1, pp. 204 y 225, respectivamente. 
[...] por quanto la dita ciudat ha en grant devocion et reverencia los gloriosos martires senyor sant Ffavyan e sant Sevastian de los \quales/ en cada un anyo se faze grant fiesta e solempnidat en el monasterio del Carmen de la dita ciudat e por tal que sian intercessores con Nuestro Senyor Dios que por su infinida clemencia quiera guardar e preservar aquesta ciudat de toda pestilencia es stado deliberado que la fiesta de los ditos Santos Martires sia tenida e guardada daqui adelant cada un anyo en la dita ciudat. ${ }^{21}$

El resto de las procesiones ordinarias en honor a los santos o ángeles guardan una relación más estrecha con la ciudad. Este es el caso de la fiesta de los Santos Inocentes, ${ }^{22}$ en la que se procesionaba al Hospital de santa María de Gracia partiendo de la Seo a las 7 horas. En 1486, el pregón nos informa de que el sermón estuvo a cargo del «reuerent maestre Benet, ffrayre del Monesterio de Santa Maria de Jhesus», ${ }^{23}$ convento de hermanos franciscanos fundado en 1447 y situado en el arrabal de Altabás. No sabemos nada más de la identidad de tal predicador, pero el hecho de que se especifique su nombre parece indicar que se estaría recurriendo a una figura conocida para atraer a una mayor cantidad de público.

La relación de esta fiesta con el Hospital de Gracia ha sido explicada por Raúl Villagrasa en su libro sobre la red hospitalaria en Aragón:

El término «inocentes» hacía referencia a los niños, o en el caso del Hospital de Nuestra Señora de Gracia, los expósitos de los que se hacía cargo [...] En segundo lugar, los dementes también comenzaron a identificarse en época medieval con estos Inocentes [...] Es interesante observar que ambas fechas, el 28 de diciembre y el 8 de enero, y ambos grupos, huérfanos y dementes, comparten festividades en época medieval [...] Tanto unos como otros, expósitos y locos, siguieron siendo mantenidos por el Hospital de Nuestra Señora de Gracia más allá del siglo XVI. (Villagrasa, 2016: 65-68)

La implicación del Concejo en esta institución es evidente ya que, para su sostenimiento, el Hospital contaba con rentas administradas por el municipio (Muñoz, 1944: 150); además, parte de la recaudación de las multas impuestas por el Concejo se aplicaban al Hospital, como refieren los pregones en múltiples ocasiones: «...dius pena de veint sueldos yrremisiblement levaderos de

21 PRE-02, cuadernillo 4, f. 18v.

22 Esta fiesta sufrió variaciones en el calendario. El pregón del 7 de enero 1486 convoca a los fieles al día siguiente ( 8 de enero), mientras que la crida de 1500 es del 30 de diciembre (más cercana a nuestra fecha del día 28 de diciembre).

23 PRE-01, cuadernillo 1, f. 8r. 
aquell o aquellos que contra lo sobredicho en cosa alguna vendran aplicaderos al spital de santa Maria de Gracia». ${ }^{24}$

Devociones comunes en la Corona eran san Jorge y el Ángel Custodio. Hay que apreciar en ellas su importancia para la construcción de la identidad de Zaragoza como capital del reino de Aragón, un reino que era, a su vez, cabeza simbólica de la Corona. Disponemos de cuatro pregones de la fiesta de san Jorge (23 de abril): el de 1472 — con procesión a la capilla de san Jorge en la Aljafería - y los de 1478, 1479 y 1486 a la iglesia de santa María del Temple.

La figura de san Jorge estuvo desde su aparición vinculada a la milicia cristiana. Desde finales del siglo XI su culto esta atestiguado en tierras catalanas y aragonesas, «proliferando apariciones como San Jorge Matamoros en las batallas contra los infieles» (Narbona, 1996: 316). Pedro IV (1336-1387) impulsó la devoción a san Jorge en la Corona de Aragón como santo protector en la batalla. Así, durante la guerra contra Pedro I de Castilla, los ejércitos aragoneses avanzaron tras la enseña del santo (Narbona, 1996: 316) y los obispos le dedicaron misas diarias para lograr su favor (Lafuente, 2008). La devoción a san Jorge se generalizó en muchas partes de la Corona. En Valencia, por ejemplo, la fiesta se observaba ya en 1343 y en Zaragoza se dedicaba una capilla al santo en el palacio de la Aljafería unos años más tarde. En 1407 comenzó a celebrarse fiesta en Mallorca y en 1456 en Cataluña. Sin embargo, hubo que esperar a 1461 a que Juan II ordenara que fuera fiesta oficial en Aragón, como recuerdan dos de las cridas del Concejo ( 22 de abril de 1478 y 22 de abril de 1479):

[...] por solempnizar la fiesta del glorioso Senyor sant Jorge [...] porque el Senyor Rey manda ffestivar la ffiesta juxta los actos de la cort de Calatayut se ffazen solempne processione en la fforma e manera que se ha acostumbrado fazer en Valencia e en otros regnos. ${ }^{25}$

Se trata de una fiesta fomentada desde el poder y que se refuerza en la baja Edad Media. La festividad se ha de guardar por orden del rey, del Padre Santo y de los Fueros del Reino con la solemnidad del domingo, es decir, sin realizar trabajo alguno. No hablamos aquí de una devoción popular sino más bien de la nobleza y de la monarquía, institución que se sirvió de la figura de 
san Jorge como instrumento para aglutinar al estamento militar y asentar su poder.

\begin{abstract}
Esta relación entre monarquía y divinidad es un fenómeno bastante generalizado en Europa a partir del siglo XIII, y está en consonancia con el fortalecimiento del poder monárquico en la configuración de los grandes estados europeos. La monarquía inglesa, por ejemplo, conoció una vinculación especial también a San Jorge expresivamente documentada; mientras la castellana, por su parte, continuó desarrollando su relación con Santiago. (Lafuente, 2008: 435-336)
\end{abstract}

Los pregones de los años 1478, 1479 y 1486 anuncian procesiones en honor a san Jorge con destino a la desaparecida iglesia de Santa María del Temple, en plena guerra con el reino de Granada. De forma excepcional, en 1472, la ciudad había acudido por la fiesta y en procesión de acción de gracias a la capilla de san Jorge en la Aljafería. El motivo hay que encontrarlo en el hecho de que el futuro Fernando II se encontrara residiendo en el palacio. Unos días antes, había entrado en la ciudad bajo palio y ahora príncipe y reino celebraban la recuperación del Rosellón y la Cerdaña, territorios patrimoniales del rey de Aragón desde Jaime I y — debido a las tensiones en Cataluña- en litigio con Francia.

[...] gracias a Nuestro Senyor Dios de la rendicion fecha de la villa de Perpinyan e todo el condado de Rossellon e Cerdanya a la obediencia e dominio del Senyor Rey es deliberado fazer solempne procession cras jueves dia del glorioso martir e cavallero Sant Jorge a la capiella e yglesia suya de la Aljafferia. ${ }^{26}$

La fiesta del Ángel Custodio y su auge en la Corona de Aragón a finales de la Edad Media fue estudiada por Llompart ya en los años 70 y 80 del siglo xx. Para este autor, se trató de un culto fundamentalmente municipal. Los ayuntamientos actuaron de intermediarios entre la piedad litúrgica y la piedad popular y sacaron la fiesta de sus capillas a las calles (Llompart, 1988: 252254). En el caso de Zaragoza, menciona la existencia de una capilla del Ángel en las Casas del Puente en $1479 \mathrm{y}$ de un ordenamiento municipal que regulaba la fiesta desde 1493.

La comitiva solemne que sale de las Casas del Puent o Ayuntamiento hacia la Seo, donde tiene lugar el oficio, va presidida por una bandera con la 
figura del Custodio y las armas de la ciudad [...] La porta el jurado cuarto o quinto, al que flanquean, en guardia de honor, dos consejeros municipales. (Llompart, 1988: 256)

Aunque este autor afirma que esta fiesta solo nos es conocida por el ordenamiento de 1493, las cridas nos proporcionan una descripción muy similar para el año 1500:

[...] façer procession general en cada y un anyo del dicho Angel Custodio et levar la bandera et figura de aquel en aquella, la qual fiesta et procesión sea de façer cras domingo. Por tanto dizen, intiman et mandan que cras domingo, a las seys horas, sean plegados et ajustados a la Seu uno de cada casa para acompañar la dicha procession, la qual partira de la Seu yra por la Freneria et Cuchilleria al cap de la carrera et a Sant Per, a las Botigas Fondas, la Carrera Nueva adelante al Mercado et volvera la Carrera Mayor abaxo, al cap de la carrera, a Sant Jayme drecha via por la Cuchillerya, a la plaça et a la Seu et a donde se fara el officio et sermon. ${ }^{27}$

Son estas, sin embargo, fechas muy tardías para una devoción que, en otros reinos de la Corona, parece estar en marcha desde finales del siglo xIV. En este sentido, los pregones del Concejo hacen posible remontar la fiesta del Ángel Custodio varias décadas al dejar testimonio de la existencia de una fiesta ya en los años 50 del siglo Xv, aunque no vinculada a las casas consistoriales. El 20 de junio de 1450 los jurados de la ciudad ordenan anunciar la celebración de una procesión al monasterio del Carmen con motivo de la fiesta del Ángel Custodio. Se insta a los vecinos a participar en la misa y sermón, ya que el arzobispo otorgará por ello 120 días de indulgencia. ${ }^{28} \mathrm{El}$ destino procesional es el mismo en 1455, aunque en este caso la fecha del pregón es el día 17 de mayo y sabemos que la procesión tendrá lugar en domingo. Parece que en la década de los 50 existe ya una devoción relacionada con el monasterio del Carmen, sin una fecha determinada entre los meses de mayo y junio. Esto encajaría mejor también con la existencia de imágenes como la de Pero Joan realizada antes de 1450, para ser colocada en la Puerta del Ángel de la ciudad o el retablo de la capilla de las Casas del Puente:

No sabemos cómo era dicho retablo, pero la tradición dice que la imagen del Ángel Custodio de alabastro atribuida a Pere Joan, hoy conservada en el Museo de Zaragoza (inv. 156), era propiedad de la casa consistorial y que 


\begin{abstract}
pudo trasladarse posteriormente a la Lonja de mercaderes, construida justo detrás de las Casas del Puente. En nuestra opinión, si en la capilla de las Casas del Puente había un altar con dicha advocación, y teniendo en cuenta que allí había trabajado Pere Joan hacia 1443, podría conjeturarse que la escultura hoy custodiada en el museo procedería del retablo que se menciona en 1496. Una opción plausible es que los patronos de este segundo altar de la capilla del consistorio - si es que los años cuarenta ya existía, lo que a día de hoy no podemos corroborar con documentos-, encargasen la obra al artista que poco antes había ejecutado el retablo que presidía el altar principal. (Velasco, 2014-2015: 333 y 335)
\end{abstract}

Desde el monasterio del Carmen, la fiesta cambió de emplazamiento antes de 1481, fecha en la que la crida de la procesión por san Gregorio y san Lamberto nos informa de que la celebración tiene ya lugar entonces, como explicaba Llompart, en la capilla de las Casas del Puente. ${ }^{29}$

Dos santos locales cierran este apartado: san Braulio (obispo de Zaragoza en el siglo VII) y san Lamberto (santo agricultor martirizado en la ciudad en el siglo Iv). Aunque en el santoral romano se dedica el 26 de marzo a la festividad de san Braulio, parece que en Zaragoza se celebraba antes del día 18 (Fatás, 2009: 12) si bien la única crida que menciona esta devoción no señala ni el día ni el mes. En 1452, el arzobispo de Zaragoza ordena que la ciudad conmemore al santo, antiguo obispo de la ciudad, todos los años y que se haga procesión a la iglesia de Santa María la Mayor. El orgullo de la ciudad por contar entre sus hijos con figura de tal erudición es parejo con el que demuestra sentir por el humilde agricultor Lamberto, decapitado al negarse a abjurar de su fe en 304 , y al que se denomina «conciudadano de aquesta ciudat». ${ }^{30} \mathrm{La}$ devoción a san Lamberto está íntimamente ligada al voto de la ciudad a san Gregorio, motivo por el que ambos santos se estudiarán juntos en el apartado siguiente.

Tanto en el caso de san Braulio como en el de san Lamberto sus cultos se vinculan a la existencia en la ciudad de las reliquias de sus cuerpos. Estas cumplen una doble función: por un lado, son muestra viva y palpable de la presencia de Dios, fuente directa del poder divino, cuya principal misión es la de realizar milagros y prodigios; por otro, forman parte de las tradiciones y signos identitarios que la ciudad considera un deber proteger. En el caso de San Braulio, el pregón nos informa de que «su cuerpo yaçe en la yglesia de 
Santa Maria la Mayor de la dita ciudat», ${ }^{31}$ f actor que contribuyó a revivir la memoria del santo.

La invención del cuerpo de San Braulio, obispo de Zaragoza (631-651), bajo el atrio de Santa María la Mayor seguida de su traslado al presbiterio del templo cesaraugustano junto al relato de los primeros milagros que obró aparece descrita en un pergamino fechado en 1272 que se conserva en el Archivo de Nuestra Señora del Pilar, de cuyo contenido se conoce una segunda versión del siglo XIv en la Biblioteca Nacional de Francia. En dicho documento descansa una tradición constante y mantenida hasta hoy que sitúa los restos del prelado bajo el altar mayor de la basílica, de donde sólo han sido movidos en circunstancias excepcionales. (Ainaga y Criado, 2008: 66)

El aprecio de la ciudad por estas reliquias es visible en la existencia ya en 1312 de dos relicarios de la cabeza y del brazo del obispo (Ainaga y Criado, 2008: 68); sin embargo, los pregones estudiados nunca mencionan su cabeza como una de las que desfilaban por las calles de la ciudad en los momentos más solemnes. La exposición de estos objetos sagrados a la vista, el más poderoso de los sentidos según los teólogos medievales, ejercía una influencia moral, incitaba a la piedad y coadyuvaba al efecto que producían los himnos, cantos, antífonas y sermones. La figura 2 muestra el empleo de los relicarios con las cabezas de los santos en el periodo estudiado. ${ }^{32}$

En el caso de las procesiones del Corpus Christi, se registra la presencia de los bustos relicarios (denominados cabezas en las fuentes) de santa Engracia y san Lamberto desde 1474, a los que se añadió en 1486 el de santa Bárbara, continuando sin interrupción hasta el final del periodo. Este hecho guardaría relación con la mayor solemnidad de la fiesta e implicación del Concejo a medida que van pasando los años (como se ha hecho notar con anterioridad). Los pregones nos informan también del aviso a los vecinos (tanto cristianos como moros) de la obligación — bajo pena de veinte sueldos — de mantener limpias las calles por las que habrían de pasar las reliquias, tal y como corresponde al

31 PRE-02, cuadernillo 2, f.10r.

32 Según Criado Mainar (2000:215-216), estos relicarios corresponderían a la donación hecha por Benedicto XIII a la Seo del Salvador de Zaragoza: tres esculturas de plata y esmaltes de los santos Valero, Lorenzo y Vicente, que procedentes de Avignon, llegaron a Zaragoza en 1406, y una cuarta, hoy desaparecida, destinada a custodiar el cráneo de santa Engracia en el santuario de las Santas Masas. Sobre las otras dos piezas, se conoce que la que albergaba los restos de san Lamberto fue ordenada por los regidores de la iglesia de Santa Engracia hacia 1465. Menos información se dispone del busto relicario en plata, no conservado, de santa Bárbara del convento del Carmen, que parece haber servido de modelo para una imagen de Juan de Salazar en 1510 (Criado, 2014: 348). 
decoro y respeto debido a las mismas. En algunas ocasiones especiales (e.g. 1477, 1478 ó 1486), la víspera de la procesión general se organizaba otra para acompañar las cabezas de los santos desde la iglesia de Santa Engracia a la Seo, donde pasaban la noche.

\begin{tabular}{|l|l|l|}
\hline AÑO & MOTIVO PROCESIONAL & RELIQUIA (cabezas) \\
\hline 1474 & Corpus Christi & Santa Engracia \\
\hline 1476 & Corpus Christi & Santa Engracia y san Lamberto \\
\hline 1477 & Rogativa lluvia y sanidad & San Lamberto \\
\hline 1478 & Rogativa lluvia y sanidad & Santa Engracia y san Lamberto \\
\hline 1479 & Corpus Christi & Santa Engracia y san Lamberto \\
\hline 1480 & Corpus Christi & Santa Engracia y san Lamberto \\
\hline 1481 & Corpus Christi & Santa Engracia y san Lamberto \\
\hline 1486 & Corpus Christi & Santa Engracia, san Lamberto y santa Bárbara \\
\hline 1486 & $\begin{array}{l}\text { Acción de gracias victoria del rey y } \\
\text { festividad de san Gregorio y san Lamberto }\end{array}$ & Santa Engracia y san Lamberto \\
\hline 1488 & Corpus Christi & Santa Engracia, san Lamberto y santa Bárbara \\
\hline 1488 & Acción de gracias victoria del rey & San Vicente y san Lorenzo \\
\hline 1500 & Corpus Christi & Santa Engracia, san Lamberto y santa Bárbara \\
\hline
\end{tabular}

Figura 2. Empleo de relicarios en procesiones zaragozanas. (Elaboración propia).

\subsubsection{Los patronos y votos de la ciudad}

Si alguna devoción identifica a Zaragoza de forma clara es la de sus santos patronos y los votos hechos por la ciudad: santa Engracia, los santos Mártires y san Gregorio, todos ellos vinculados a la iglesia de Santa Engracia, como se explicará a continuación.

Entre 1450 y 1480, siete pregones nos informan de la convocatoria de procesión con motivo de la festividad de san Gregorio. La pregunta que cabe hacerse es ¿de qué san Gregorio se está hablando? Parece existir cierta confusión o quizá asimilación entre san Gregorio Magno — sexagésimo cuarto papa y uno de los Padres de la Iglesia (540-604) — cuya persona se conmemora el 12 de marzo, y san Gregorio Ostiense, fallecido en 1044 y cuya fiesta se celebra el 
9 de mayo. Los pregones del 11 de marzo de 1450 y del 10 de marzo de 1459 convocan procesiones al monasterio de Predicadores, en do la invocación del dito santo es. ${ }^{33} \mathrm{La}$ fecha es claramente indicativa de que se trata de san Gregorio Magno y, por lo que respecta al destino de la procesión, sabemos que en 1493 el convento de Predicadores de Zaragoza encargó en 1493 al platero Pedro Durant un busto relicario para custodiar reliquias de este papa (Criado, 2000: 220). Tanto la crida de 1459 como otra de 1470 especifican claramente que la procesión de san Gregorio se hace por honor de senyor sant Gregorio papa. ${ }^{34}$

En 1450 la procesión parece ser más una rogativa por buen tiempo que una procesión ordinaria; sin embargo, todo cambia en 1458 con una plaga de langosta. Según el pregón de 1459, la procesión se convoca por honor de senyor sant Gregorio papa a suplicacion del qual Nuestro Senyor Dios quiso tirar en el anyo passado la lagosta ${ }^{35}$ coletilla que a partir de entonces aparecerá en todos los pregones por la fiesta del santo. La vinculación de san Gregorio Magno con la langosta persiste todavía en el siglo XVII y Juan de Quiñones (1620: cap. III, ff. 50r. y 51v.) nos proporciona una explicación: en tiempos del papa Estéfano VI las langostas cubrían la tierra por lo que el pontífice rezó a san Gregorio Magno, bendijo agua con la que se regaron los campos y las langostas cayeron muertas. Pero un poco más adelante el mismo autor menciona una historia parecida protagonizada por san Gregorio Ostiense: debido a una plaga de langosta y pulgón persistente, los habitantes de Calahorra, Pamplona y Tarazona acudieron al papa, que envió a Gregorio, obispo de Ostia. Tras misas y penitencia las langostas huyeron y los campos quedaron limpios. ${ }^{36}$

No tenemos registros entre 1459 y 1462 relativos a la devoción a san Gregorio, pero en 1463 descubrimos que la procesión ha cambiado de destino (a partir de ahora y hasta el final de la serie se encamina a Santa Engracia) y de fecha (primero en un día variable en el mes de junio y, desde 1481, el día 19 de ese mes). Además, en $1481^{37}$ (aunque solo en ese año), el santo cambia ligeramente de nombre y pasa de denominarse Gregorio a Gorgonio. Criado Mainar (2000: 219) hace referencia al encargo a Pedro Durant en 1497 de un segundo busto relicario: esta vez para custodiar las reliquias de san Gregorio Ostiense

33 PRE-02, cuadernillo 5, f. 9r.

34 PRE-02, cuadernillo 10, f. 25v.

35 PRE-02, cuadernillo 5, f. 8v.

36 Para más información sobre la devoción a san Gregorio Ostiense se puede consultar el artículo de Barragán mencionado en la bibliografía.

37 PRE-03, f. 16v. 
en la iglesia de San Pablo. Curiosamente, el documento que incluye este autor en el apéndice nos habla de una testa o cabeça de argent de Sant Guorguonio con cuerpo e mitra de obispo (Criado, 2000: 232), lo que coincide con el cambio de denominación del santo en el pregón y apunta a una desviación o una convergencia en la devoción a los dos santos.

Sea uno u otro Gregorio, los pregones nos informan de que se prohíbe toda actividad económica hasta que acabe la procesión «como sia voto de la ciudat». ${ }^{38}$ El cambio en el destino procesional a la iglesia de Santa Engracia en 1463 podría estar relacionado con la custodia en este templo de la reliquia de la cabeza de san Lamberto - mencionada en el apartado anterior, y cuya festividad se celebra el 19 de junio - y el intento de las autoridades de enaltecer la figura del santo local. Como hemos indicado, la fiesta pasa de marzo a junio y en 1481 se ordena que en adelante san Gregorio y san Lamberto se celebren juntos el día 19 de junio:

Et por quanto la dicha festividat de Senyor Sant Lambert fasta aqui concorria con la fiesta del Angel Custodio, que se celebra en la capilla de las Casas del Puent, et no podia ser festivada como requeria al servicio de Nuestro Senyor Dios et honor del glorioso martir conciudadano de aquesta ciudat, el vicario general de voluntad de la dicha ciudat ha mandado para cras martes, dia de Sant Gorgorio, que la dicha festividat de Senyor Sant Lambert sia festividat, el qual dia sia guardado assi como el dia del domingo. ${ }^{39}$

Para mayor solemnidad, y en adelante, veremos cómo los pregones indican que los jurados que estén en la ciudad se reúnan en las Casas del Puente y acudan, junto con el capítulo y otros ciudadanos, a oír vísperas a Santa Engracia al son de trompetas, atabales y tamborinos. ${ }^{40}$ La música, además de realzar la procesión y darle un sentido festivo, silencia las voces y los murmullos, proporciona ritmo a la marcha de los procesionantes y coordina sus movimientos para que todo el grupo camine al unísono. La procesión del día siguiente partía a las siete de la mañana con destino a Santa Engracia, prohibiéndose en tal día

[...] albardar bestia alguna ni cargar cargueria alguna, parar tiendas, ni fazer fazienda alguna que sea crebantamiento de la dicha fiesta dius pena de vint sueldos yrremissiblement levaderos de aquel o aquellos que contra lo sobredicho en cosa alguna venran. ${ }^{41}$

38 PRE-02, cuadernillo 11, f. 19v.

39 PRE-03, f. 17 r.

40 PRE-03, ff. 16v.-17v.

41 PRE-01, cuadernillo 3, f. 17v. 
El martirio de santa Engracia y sus dieciocho compañeros en 303 dio lugar a una devoción que ha pervivido casi sin interrupción hasta nuestros días. Es un ejemplo de elaboración, rememoración y vinculación de estas figuras a la ciudad, que sirve a esta como elemento identitario desde que el primer sínodo provincial de la Tarraconense en 592 instituyera la fiesta de los Innumerables Mártires el 3 de noviembre. El templo de las Santas Masas, que alberga los restos de estos mártires cristianos, mantuvo vivo su recuerdo incluso en época musulmana.

En el año 985, debido al asalto de Barcelona por Almazor, un cristiano llamado Moción, hijo de Fruia, fue hecho prisionero y llevado a Córdoba. Después logró volver a Zaragoza, donde murió en el 986. Al hacer testamento dejó a «Sancta María que est sita in Çaragotia y a las Santas Masas qui sunt foris muris», cien sueldos. (Cía, 2001-2002: 22-23)

Ambas devociones dieron lugar a dos procesiones anuales (16 de abril y 3 de noviembre), a las que hay que sumar la ya mencionada de san Gregorio al mismo templo. De esta forma, esta iglesia se convirtió en el destino procesional más frecuente en la segunda mitad del siglo XV en Zaragoza (Figura 3).

NÚMERO DE PROCESIONES ENTRE 1450 Y 1459

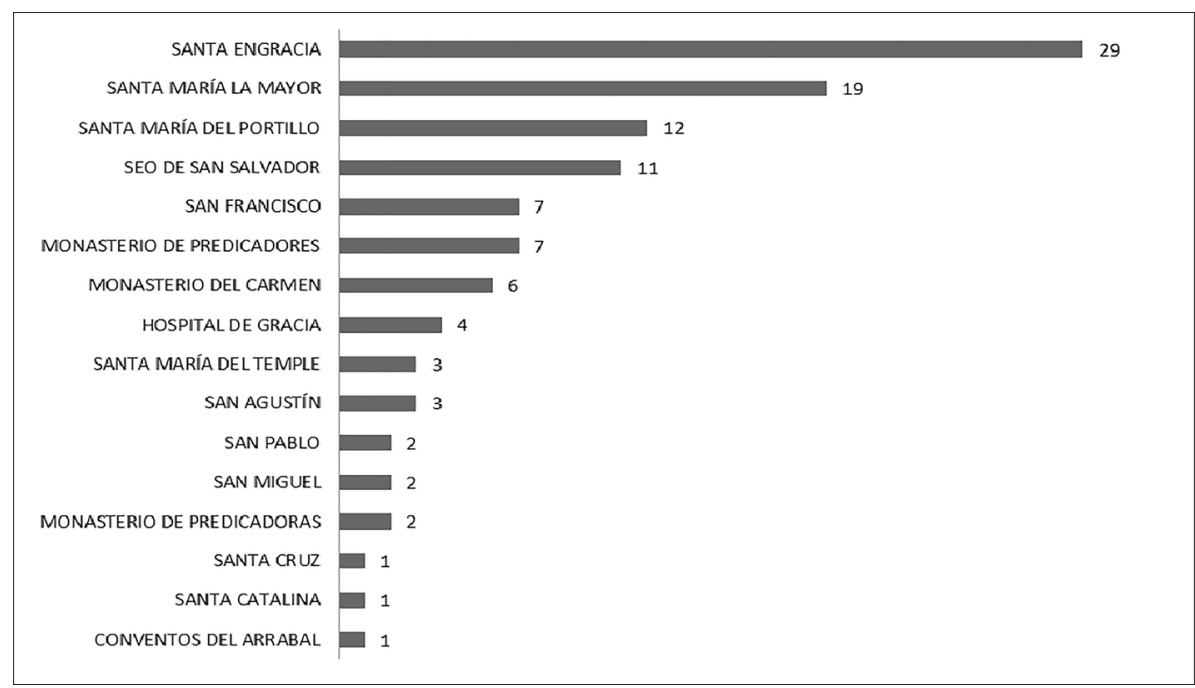

Figura 3. Destinos procesionales en Zaragoza entre 1450 y 1500.

(Elaboración propia). 
Desde el siglo XI la iglesia de las Santas Masas estuvo vinculada al obispo de Jaca (en 1063 Paterno, obispo de Zaragoza, realizó la cesión) y a la sede de Huesca. Tras la conquista de la ciudad en 1118 el obispo don Pedro de Librana ratificó la donación además de ceder al obispo de Huesca la parroquia de San Gil y otros territorios. ${ }^{42}$ La iglesia de las Santas Masas o de Santa Engracia aparece mencionada en documentos de los siglos XIII y XIV, como dos bulas papales de 1206 (del papa Alejandro VI) y 1300 (del papa Bonifacio VIII), dejando constancia de la importancia de este templo en la ciudad (Cía, 20012002: 24-26).

Siguiendo los datos aportados por Cía Blasco (2001-2002: 30-38), en 1320 reaparecieron los restos de la santa y se produjo un significativo avance en la devoción por parte de la ciudad. En 1405 Benedicto XIII regaló a la iglesia de Santa Engracia un busto relicario para custodiar la cabeza de la mártir lusitana y en 1423 quedó fijado el voto de acudir en procesión a la iglesia de las Santas Masas, voto al que hace mención, por ejemplo, un pregón de $1450 .{ }^{43}$

En 1431 llegó a la sede de Zaragoza el arzobispo Dalmau Mur, quien impulsó obras de renovación en el templo. Estas obras son mencionadas en el pregón de santa Engracia de 1455, en el que se prohibió levantar fiemos debido al mal olor que entraba en la iglesia. Un tercio de la multa impuesta, si se contravenía la orden, iría a parar a las obras de la iglesia (otro tercio a las del puente y otro tercio al acusador).$^{44} \mathrm{La}$ importancia que fue adquiriendo no sólo el templo sino también la devoción a la santa está reflejada en la prevalencia de esta festividad sobre otras de la ciudad. Es lo que ocurre en 1465, año en el que la procesión al Hospital de Gracia con motivo del martes de Pascua se pospuso al domingo siguiente por haber sido el martes día de santa Engracia y haberse celebrado su fiesta. ${ }^{45}$

En 1480 Santa Engracia fue declarada patrona de la ciudad y se redactó el estatuto sobre su festividad, que quedó fijada definitivamente el 16 de abril (día en el que ya se venía celebrando). Y la fiesta de los Innumerables Mártires se mantuvo el 3 de noviembre. A partir de esta fecha, los pregones de santa Engracia se vuelven más elegantes en el lenguaje e incorporan las razones de la celebración:

42 El artículo de Cía Blasco aporta información sobre las vicisitudes de este templo en relación con su dependencia de la Iglesia de Jaca y de Huesca.

43 PRE-02, cuadernillo 1, ff. 1v. y 12r. y f. 33v.

44 PRE-02, cuadernillo 4, ff. 10v. y 11r.

45 PRE-02, cuadernillo 7, ff. 12rv. 
(...) attendidos los muchos miraglos que en la present ciudat se han fecho y fazen continuament por la intercession de los gloriosos y bien abenturados Martires que en ella recibieron martirio por la fe de Nuestro Senyor Jesuchristo Dios y redemptor nuestro y actendida la mucha devocion que la ciudat tiene en la Casa de Senyora santa Engracia patrona qui es de aquella. ${ }^{46}$

Además de la procesión —en la que se reparte limosna a niños y pobresse celebraron vísperas en Santa Engracia, a las que debían acudir los jurados que se encontrasen en la ciudad, el capítulo y el consejo acompañados de trompetas, atabales y tamborinos.

\subsection{Procesiones ocasionales o extraordinarias}

Son estas procesiones las que nos hablan más claramente de las verdaderas preocupaciones de la ciudad y de la implicación de las autoridades civiles en su devenir diario. La figura 4 muestra los cuatro motivos procesionales extraordinarios en el periodo estudiado y el claro predominio de las rogativas y acciones de gracias relacionadas con el clima, las pestes o las plagas $(62 \%)$.

\subsubsection{Rogativas y acciones de gracias relacionadas con el clima, las plagas o las pestes}

En una economía de base agrícola, el clima y las plagas conformaban uno de los principales desvelos de los ciudadanos y sus dirigentes. Un mal año podía dar lugar a hambrunas, muertes y disturbios en la ciudad, y las autoridades eran conscientes de la importancia de una cosecha adecuada para el bienestar de la res publica. En los registros estudiados, destacan los años 1450, 1455 y 1478, aunque la falta de datos en algunos hace que el panorama que arrojan los Libros de Pregones resulte en este sentido parcial. Buesa Conde (1987: 48-49), utilizando los libros de Actos Comunes, refiere:

— una sequía en 1471 (año que no aparece en los pregones), que limitó los gastos de la procesión del Corpus;

— una mala cosecha de cereales en 1477 (año para el que disponemos de dos rogativas) y 1490 ;

- una plaga de langosta en 1494;

— brotes de peste en 1450, 1468 y 1495 (años para los que no disponemos de pregones). 


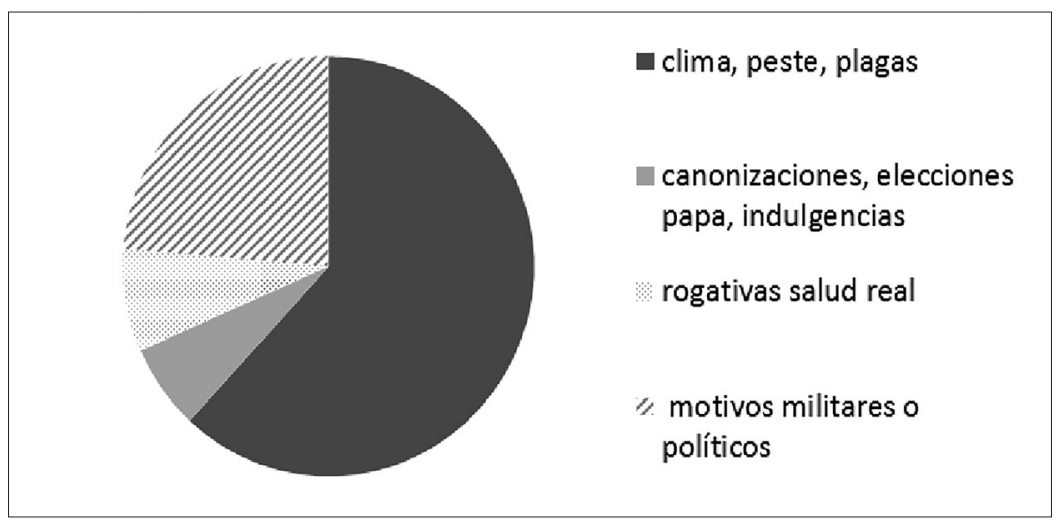

Figura 4: Motivos procesionales extraordinarios, 1450-1500. (Elaboración propia).

No obstante, no hace mención del año 1478 para el que, además de contar con siete cridas de rogativa, disponemos de un ejemplo de rogativa múltiple en el que el mismo pregón anuncia cinco procesiones diferentes en días sucesivos: «fazer cinquo solempnes processiones porque Nuestro Senyor Dios por su santa clemencia quiera tirar la pestilencia de aquesta ciudat. $\gg{ }^{47}$ Las autoridades pidieron máxima devoción en las procesiones y que los participantes llevasen candelas encendidas. Dos cridas más adelante, da la sensación de que esta rogativa no fue del todo eficaz y la ciudad dispuso organizar una nueva procesión a Santa María del Pilar. La preocupación de las autoridades parece extrema y para que Dios escuchase los ruegos de su pueblo, atemorizado por el peligro de la peste, las cabezas de santa Engracia y san Lamberto salieron en la comitiva y se ordenó que mozas y niños descalzos las acompañasen.

En otras ocasiones se organizaron las rogativas por buen tiempo o sanidad aprovechando la celebración de procesiones ordinarias, especialmente las de san Gregorio y san Lamberto (relacionadas con las plagas de langosta), san Fabián y san Sebastián, el Ángel Custodio, etc. Si todo fallaba, la ciudad contó con otras devociones a las que recurrir:

- En el monasterio de San Agustín, santa María de Piedad, (dos procesiones en 1450 y una en 1470). ${ }^{48}$

47 PRE-02, cuadernillo 15, f. 19r.

48 San Agustín era invocado en muchos pueblos de la Península como protector especializado contra la langosta. 
- En el monasterio de Predicadores, san Pedro Mártir, santa María del Milagro, santa María del Rosell y san Vicente. ${ }^{49}$

- En el convento de Altabás, san Marcos (25 de marzo). ${ }^{50}$

- En la iglesia de San Miguel de los Navarros (procesión en 1455) y en la capilla de san Miguel de la Seo (procesión en 1463 y 1470), san Miguel Arcángel. ${ }^{51}$

- En el monasterio de San Francisco, san Bernardino (célebre predicador franciscano); en el monasterio de las Predicadoras, san Cristóbal; en el monasterio de las Clarisas de Santa Catalina, santa Catalina de Alejandría; en el monasterio del Carmen, santa María de la Consolación; en la iglesia de Santa Engracia, la Virgen de los Mártires y en la iglesia de San Pablo, santa María y san Blas.

\subsubsection{Procesiones relacionadas con la salud real}

Entre 1462 y 1479 Zaragoza estuvo preocupada por la salud de Juan II y se multiplicaron las procesiones rogativas a la Seo, Santa María del Pilar (templos relacionados con la monarquía) y San Miguel de los Navarros (arcángel de cualidades sanadoras). El rey sufría de gota, estaba casi ciego y había tenido que delegar funciones de gobierno en su hijo Fernando, al que había nombrado recientemente rey de Sicilia. Las procesiones por su salud tuvieron un carácter solemne, quedando prohibido que la ciudad recuperase su ritmo económico hasta que se hubiera dado por concluido el ritual: «ninguno no sia ossado obrar ni parar tiendas fasta que la dita procession sia pasada. $\rangle^{52} \mathrm{La}$ preocupación se dispara en 1479 y se ordena procesión solemne «por suplicar a Nuestro Senyor Dios quiera dar salut al senyor rey porque esta enfermo.. ${ }^{53}$

49 Los pregones no lo especifican pero debe tratarse de san Vicente Ferrer, predicador dominico, canonizado en 1455 por Calixto III. De este santo se conoce su intervención en Murcia en 1419, ciudad a la que salvó de la langosta y el pulgón con su oración y con agua bendita.

50 La devoción a este santo continuaba una tradición romana destinada a preservar las cosechas de peligros a la par que el día coincidía con la finalización del arriendo de los pastos de invierno.

51 Príncipe del ejército celeste, conductor de almas, protector de parturientas y sanador, san Miguel es un santo polivalente, vinculado también a las pestes y a las plagas. $C f$. el artículo de Carmen García Herrero y M. a Jesús Torreblanca Gaspar (1993) sobre «San Miguel y la plaga de langosta (claves para la interpretación del voto taustano de 1421).»

52 Es bien conocida la operación de cataratas a la que Juan II se sometió y en acción de gracias por la cual mandó construir un monasterio de jerónimos en honor a Santa Engracia, obra que acometió su hijo.

53 PRE-02, cuadernillo 16, f.7v. 


\subsubsection{Celebraciones religiosas con contenido político o militar ${ }^{54}$}

Desde 1479 el reino tiene un rey joven, Fernando II, y solo en 1483 sabemos que unas calenturas han puesto en peligro su salud. ${ }^{55}$ Tras la muerte de Juan II, es el momento de la sucesión real, de la monarquía entendida como cuerpo perpetuo del rey (Kantorowicz, 1957: 314-372). Con motivo de su coronación, Fernando II multiplica su presencia en la ciudad y se hace visible en entradas reales y procesiones solemnes que establecen un diálogo entre la ciudad y el monarca y transmiten el mensaje político del poder del rey. Entre todos ellos, cabe mencionar la celebración, anunciada mediante pregón del día 6 de julio de 1479, de una solemne procesión a la Seo en la que estarán presentes las cabezas de santa Engracia y de san Lamberto. La implicación de la ciudad en el acontecimiento es total, desde sus santos patronos hasta los oficios y cofradías a los que se ordena ir en la procesión «con las luminarias en la forma e manera que acostumbran ir en la fiesta del Corpus Christi.» ${ }^{56}$

A la misma idea de la continuidad sucesoria apunta la importancia del primogénito. En 1478 otra crida anunció el nacimiento del príncipe Juan:

[...] como la senyora reyna de Castilla es parida e ha parido hun gentil principe e primogenito de Castilla. E por tanto el dicho senyor rey manda que sean fechas gracias a Nuestro Senyor Dios que ha querido bien livrar del parto a la dicha senyora reyna. ${ }^{57}$

Su calidad de primer hijo varón del entonces heredero al trono aragonés hizo que el príncipe Juan fuese también importante para la casa de Aragón. Ello fue motivo de celebraciones en la capital y razón de que el Concejo ordenase que todos acudieran a misa a la Seo para celebrar la festividad de las santas Justa y Rufina, patronas de Sevilla, ciudad donde había tenido lugar de nacimiento del príncipe Juan.

La guerra, especialmente si el reino resultaba victorioso, fue un arma de increíble efecto propagandístico para la monarquía, a la vez que proporciona-

54 En este punto no se analizan las entradas y ceremonia reales como tales sino las procesiones religiosas vinculadas con la monarquía o su política. Sobre las entradas reales en Zaragoza, vid. el trabajo de Barraqué (2008).

55 PRE-01 cuadernillo 3, f.4v. Hay que destacar que no consta en los pregones mención alguna al atentado sufrido por Fernando II en Barcelona en 1492 a manos de Juan de Cañamares.

56 PRE-02, cuadernillo 16, ff.22v. y 23r.

57 PRE-02, cuadernillo 15, f. 19r. y v. Hay que hacer notar que en el momento del nacimiento del príncipe Juan todavía no se había resuelto la Guerra de Sucesión Castellana. 
ba la ocasión de que la comunidad expresase su lealtad y su implicación con el poder mediante rogativas y acciones de gracias. Santa María la Mayor fue el destino preferente para este tipo de procesiones, especialmente a partir de 1481 y en relación con la idea de cruzada. Los pregones relacionados con las campañas militares de la monarquía en el periodo estudiado pueden clasificarse en cinco grupos:

1. Campaña por el control de Cataluña. Se convocaron dos procesiones a Santa María la Mayor y tres a Santa Engracia (dos de ellas coincidiendo con la festividad de san Gregorio). El Concejo ordenó que los vecinos se volcasen en demostraciones de alegría cuando las noticias fueran favorables.

2. Rendición de la villa de Perpiñán a la autoridad de Juan II. Inscrita en la lucha por la recuperación de los condados de Rosellón y Cerdaña (1472), un pregón de este año informa que la procesión en honor a san Jorge se convirtió en acción de gracias por la rendición de estos condados y se acompañó de grandes «illuminarias e alumatas por los campanales e otros lugares de la dita ciudat segunt en tales casos es costumbrado fazer». ${ }^{58}$

3. Guerra contra Portugal por la sucesión a la Corona de Castilla. Un pregón de $1476^{59}$ parece estar relacionado con la victoria en la primera campaña de Toro (1 de marzo de 1476) en el trascurso de la guerra de sucesión castellana, momento especialmente delicado para Fernando e Isabel. Como elemento de propaganda interna hacia su padre y hacia el propio reino, y tras la firma de la Concordia de Segovia en 1475, Fernando aparece mencionado en el pregón con el título de Rey de Castilla, lo que no vuelve a repetirse en ninguna de las cridas estudiadas. La ciudad procesionó solemnemente a Santa Engracia y celebró la victoria por la noche con hogueras, lumbres en los puntos más altos de la ciudad (campanarios) y repique de campanas.

4. Guerra cristiana contra los turcos. La invasión otomana en 1480 de Otranto — ciudad de la Corona de Aragón en el Adriático- había adquirido tintes dramáticos y su recuperación a manos aragonesas en septiembre de 1481 debió haber sido, por tanto, considerada y propagada por las autoridades como el triunfo de la universitas christiana, con el rey a la cabeza, frente a su enemigo natural. En octubre de 1481 el Concejo zaragozano se implicó en estas celebraciones con una procesión de acción de gracias a la Seo y con bai-

58 PRE-02, cuadernillo 11, ff. 13v. y 14r.

59 PRE-02, cuadernillo 13, ff. 11v. y 12r. La crida inmediatamente anterior es del día 3 de marzo y la posterior del 22 de abril. 
les, hogueras y alegrías, obligando a participar en los actos bajo la amenaza de sanción de cien sueldos. La mezcla de odio y terror que despertó el enemigo otomano se refleja con toda claridad en la Crida de la procession e alumatas de la muerte del Turquo del 12 de junio de 1481. La ciudad se hizo eco de la «gloriosa nueva que el presente dia es venida de la muerte del nefandissimo Turco et de otros capitanes, consexo et exercito suyo» ${ }^{60}$ ordenó hacer esa noche alegrías, luminarias y repiques de campanas y conminó a todos, bajo pena de cien sueldos, a limpiar los alrededores de las casas por delante de las cuales debía pasar la procesión a Santa María del Pilar.

5. Guerra de Granada. En los pregones, 1486 y 1488 son los años de la campaña granadina, de la que pueden destacarse dos aspectos: por un lado, los esfuerzos (incluidos los de las autoridades municipales) por convencer a la población de la necesidad de la empresa por el bien de la res publica y de la universitas christiana; y, por otro, el desarrollo de la política regalista de los Reyes Católicos en sus negociaciones por la renovación de la Bula de Cruzada. Los éxitos del verano de 1486 llegaron a Zaragoza y las celebraciones tuvieron lugar en seis ocasiones, bien en domingo (probablemente para no interferir con la actividad de la ciudad) bien coincidiendo con las festividades de san Gregorio, san Lamberto, san Pedro y san Pablo. Especial importancia se concedió a la toma de la ciudad de Loja y el pregón del 10 de junio explica cómo el rey «en exaltamiento de la santa ffe catolica cristiana prosiguiendo la santa empresa con su exercito contra los infieles del regno de Granada personalmente ha tomado la ciudat de Locha del regno de Granada que es ciudat en fortaleza y grandeza muy principal en el dicho regno.» ${ }^{61}$ Se ordenó la celebración con actos acostumbrados (procesiones y luminarias) pero, como propaganda, convino dar también a los vecinos un acto festivo que les hiciera recordar el día: una corrida de toros. El 25 de junio, las autoridades anunciaron la toma de las plazas de Íllora y Moclín celebrada con cohetes y ruidos por toda la ciudad, y fuegos en el campanal et cimbori de la Seu. ${ }^{62}$

Conviene hacer notar cómo las celebraciones de carácter marcadamente político se concentran entre el final del reinado de Juan II (1479) y el inicio del reinado Fernando II (figura 5). La baja Edad Media es el momento en el que muchas ciudades están construyendo, o en ocasiones poseen ya, un elaborado

60 PRE-03, ff. 15r. y v.

61 PRE-01 cuadermillo1, f. 20r y v.

62 PRE-01 cuadernillo 1, f. 24r. 
sistema de rituales cívicos. Sin embargo, estos comenzaron a quedar supeditados al creciente poder de la monarquía en la transición hacia la Edad Moderna. Este incremento bien podría ser un indicio de que algo estaba empezando a cambiar en la cultura política de la ciudad y del reino del que Zaragoza era capital.

NÚMERO DE PROCESIONES CON CONTENIDO POLÍTICO POR DÉCADAS

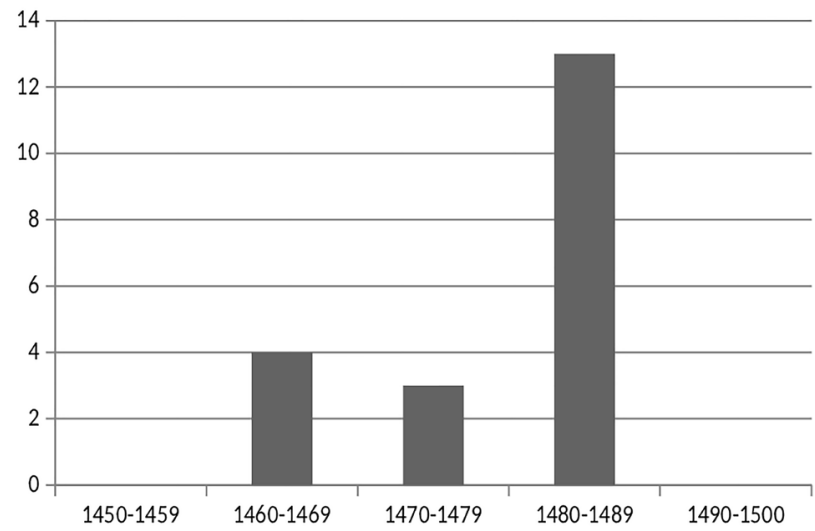

Figura 5. Procesiones con contenido político documentadas (1450-1500). (Elaboración propia).

\subsubsection{Celebraciones relacionadas con las jerarquías eclesiásticas y canonizaciones}

Además de un pregón del 13 de julio 1483 que anuncia la canonización del glorioso sant Buenaventura, ${ }^{63}$ interesa destacar aquí dos cridas de 1455 que informan de la elección del papa Calixto III y de la organización en la ciudad de sendas procesiones, la primera a San Miguel y la segunda a la Seo. Las dos procesiones son, esencialmente, rogativas contra la plaga de langosta y la peste que se aprovecharonn para dar noticia de la «eleccion de nuestro senyor el padre santo Calixto papa tercio» ${ }^{64}$ habida cuenta de que «Nuestro Senyor Dios que nos ha querido dar padre santo et vicario de Jesucristo de nuestra nacion et patria. ${ }^{65}$ En efecto, Alfonso de Borja había nacido cerca de Valencia en 1378, de familia proveniente de dicha villa zaragozana y fue elegido papa en 1455. Junto a las claras ventajas políticas que podía reportar la elección de un

63 Santo y místico franciscano nacido en la Toscana en 1218 y muerto en Lyon el 15 de julio de 1274.

64 PRE-02, cuadernillo 4, f.15 r.

65 PRE-02, cuadernillo 4, f.19 r. 
papa de la Corona de Aragón, es imposible dejar de asociar este pregón con un cierto orgullo ciudadano por el nombramiento de un compatriota y el papel que en tal orgullo juega el sentimiento de identidad y de pertenencia a una comunidad específica.

\section{Las rutas procesionales}

Las procesiones presentan algo más que el carácter ritual analizado anteriormente. Para Kuchenbuch, Morsel y Scheler (2010: 143), «les processions doivent être conçues comme des phénomènes spécifiquement spatiaux (c'està-dire des pratiques spécifiques de l'espace)». Podemos entender este espacio en una doble vertiente: el espacio interno, definido por el orden procesional de los participantes en función de su edad, sexo, posición social, etc.; para Sanmartín Arce (1988: 158), estas posiciones serían testimonio de un orden simbólico, expresivo de una jerarquía semántica. Y el espacio dibujado por la propia procesión en movimiento. A través de recorridos procesionales reiterados, la ciudad toma posesión de su territorio y conciencia de su identidad, asociando ésta a la tradición o costumbre.

Por lo que se refiere al espacio interno, lamentablemente los pregones proporcionan poca información de los participantes o del orden que ocuparían en la comitiva. Habitualmente se pide que participe una persona de cada casa — más si es posible — bajo pena de cinco sueldos. A veces, el pregón recuerda que esta persona debe ser adulta, dando al lector la sensación de que, en algunas ocasiones, esta participación podía no ser bienvenida por los zaragozanos, quienes enviaban a los niños para cumplir con la orden del Concejo. Hombres y mujeres se concentran antes de la procesión en diferentes lugares (las Casas del Puente y la Seo respectivamente) lo que parece indicar que también en la procesión ocuparían posiciones distintas. En momentos de extrema necesidad, como rogativas por la peste o lluvias, se pide que los niños vayan descalzos y las mozas, en cabellos e incluso que los cofrades acudan con candelas encendidas. Se ha comentado también anteriormente la participación de los bustos relicarios y de los músicos en las procesiones. En cuanto al orden, sólo una crida de 1500 indica que los cofrades procesionen en el lugar hordenado e graduado, sin que hayamos podido averiguar cuál era éste. ${ }^{66}$ 
Disponemos de más pistas acerca de los recorridos procesionales, sus puntos fundamentales y su importancia en la construcción del espacio urbano y en la identidad colectiva.

\subsection{Factores que conviene tener en cuenta}

Desde un punto de vista antropológico, la procesión supone la delimitación y sacralización de un espacio comunitario ligado a la figura circular del movimiento. El trayecto de la procesión no sigue siempre el camino más corto, sino que está mediatizado por varios factores.

El primero de estos factores lo constituyen las limitaciones prácticas, como el propio diseño de la ciudad, con calles estrechas por las que no podía pasar una comitiva procesional o la necesidad de evitar que la cabeza de la procesión alcanzara la cola en el momento en el que ésta salía del templo. Zaragoza a mediados del siglo Xv (Lesdesma y Falcón, 1977: 44-96) es una ciudad con un doble amurallamiento. En primer lugar, un muro de piedra que limita el espacio de la antigua ciudad romana ${ }^{67} \mathrm{y}$ en el que se abren cuatro puertas (puerta del Puente al norte, puerta de Toledo al oeste, puerta Cinegia al sur y puerta de Valencia al este) y varios trenques y postigos. Este primer reciento murado, que englobaba unas cuarenta y seis hectáreas, se mantuvo con muy pocas modificaciones tanto en su trazado original como en sus accesos principales hasta la baja Edad Media:

El muro de piedra no sólo no perdió su funcionalidad sino que conservó, también, su evidente potencial simbólico, al convertirse en el elemento que distinguía a la población encuadrada en la ciudad que, a partir de entonces, se convirtió en la gran capital de la monarquía aragonesa. (Lafuente, 2016: 233)

En segundo lugar, un muro de rejola, más exterior, que rodeaba toda la ciudad:

La superficie delimitada por la nueva muralla prácticamente triplicaba la acotada por el muro de piedra, aunque incluía tanto espacios urbanizados como amplias zonas de explotación agropecuaria. (Lafuente, 2016: 234)

La mayoría de las calles eran estrechas, con bancos y tablados que impedían un trasiego fluido, y con alternancia de huertas y viviendas. Sólo las

67 Barraqué (2008: 272) apunta a la frecuencia en la utilización de las estructuras romanas también en ciudades del sur de Francia, como Toulouse. 
calles principales - como la calle Mayor, las calles del Mercado o la calle Nueva - eran amplias y permitían que las procesiones circularan sin problemas, por lo que casi todos los trayectos hicieron uso de ellas en mayor o menor medida. Además, subir por la calle Mayor y bajar por la calle Nueva saliendo por el Mercado parecía ser un recorrido lo suficientemente estirado como para que no se encontrasen cabecera y cola de la procesión.

El segundo de los factores es el deseo de las élites ciudadanas de hacerse visibles en estas celebraciones. Debido a ello las procesiones transitaban por los lugares más representativos de la ciudad (calles anchas, mercados y plazas) y pasaban también por delante de las casas de los notables. La figura 6 muestra la situación aproximada de estas viviendas de notables, a juzgar por los recorridos procesionales descritos en los pregones. Como puede observarse, éstas se ubican entre el cap de la carrera y San Gil, a lo largo de la calle Mayor, en las proximidades de Santa María la Mayor y en las inmediaciones del Mercado, punto de máxima exposición. En esta zona, los pregones solamente mencionan la casa de don Luis de Palomar en la calle de Teresa Gil.

Finalmente hay que tener en cuenta la topografía religiosa (localización de los templos) y la importancia simbólica de algunos lugares y de la ciudad misma.

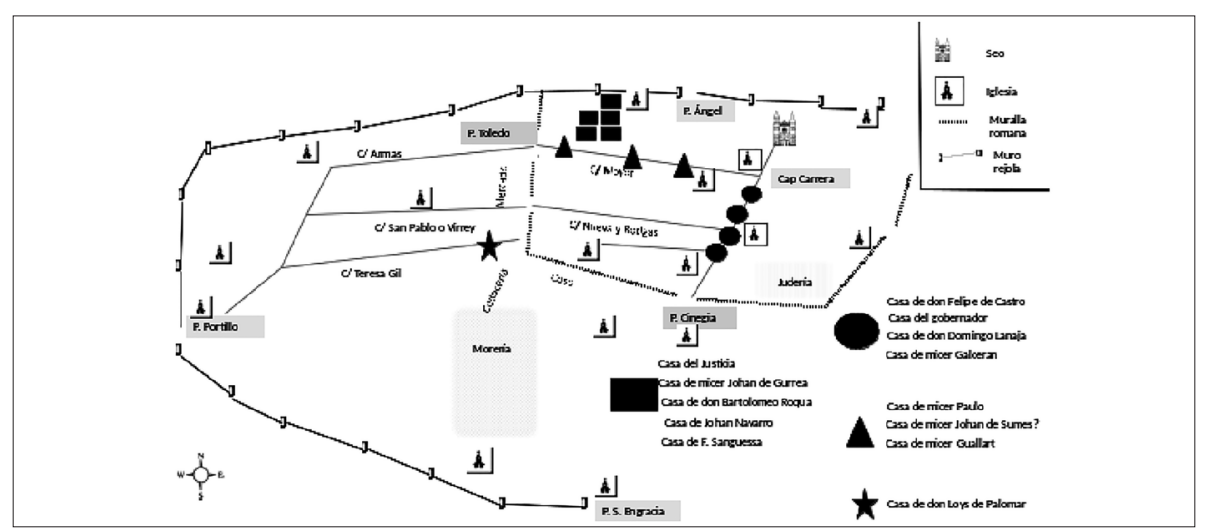

Figura 6. Ubicación de las viviendas de notables en las rutas procesionales. (Elaboración propia).

\subsection{Descripción de las rutas procesionales}

Con excepción hecha de dos rutas que partiendo desde Santa Engracia llegan a la Seo o a Santa María la Mayor para trasladar las reliquias de la santa para la procesión del día siguiente (figuras 7 y 8), todas las procesiones par- 
tieron de la Seo. La catedral es el centro del poder religioso y se encuentra situada junto al corazón político de la ciudad, las Casas del Puente. Si comparamos estas dos primeras rutas podremos observar una característica común con muchas de ellas: el camino más corto no siempre fue el preferido porque los recorridos zigzagueantes permitían que la procesión fuese más larga dando ocasión a los munícipes y sus galas de ser vistos por sus vecinos durante más tiempo. Dividiremos las rutas en dos grandes grupos: procesiones circulares y procesiones de ida y vuelta.

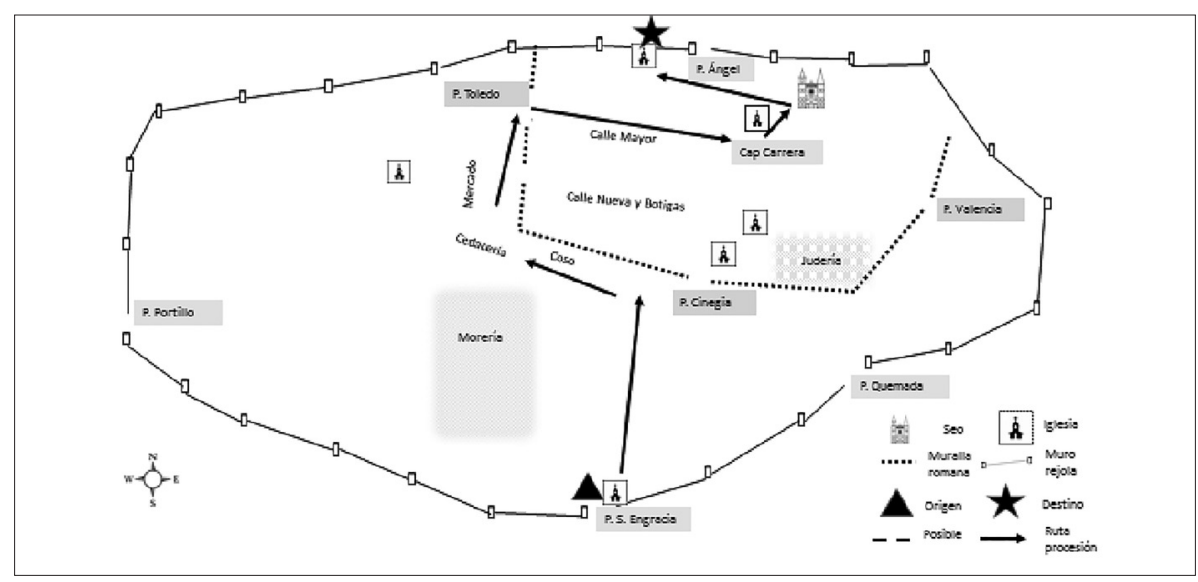

Figura 7. Traslado de las reliquias de Santa Engracia a la Seo de San Salvador. (Elaboración propia).

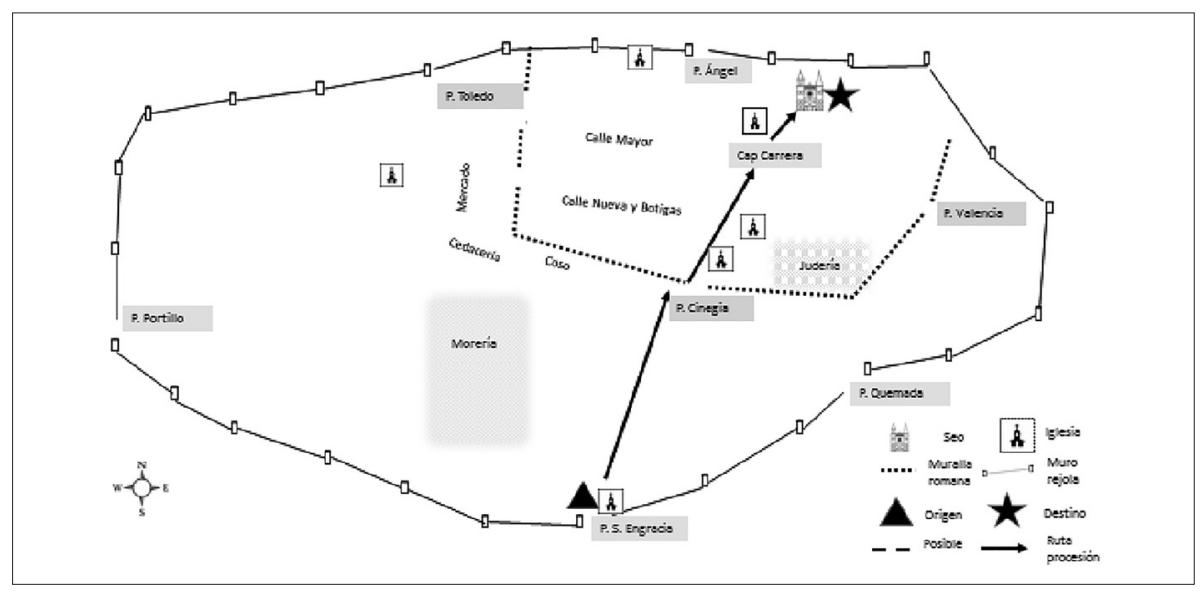

Figura 8. Traslado de las reliquias de Santa Engracia a Santa María la Mayor. (Elaboración propia). 


\subsubsection{Procesiones circulares: de la Seo a la Seo}

A este grupo corresponden fundamentalmente las procesiones del Corpus Christi. La figura 9 muestra el sentido habitual norte-sur; el sentido sur-norte (figura 10) es excepcional para el año 1454, sin que podamos llegar a adivinar el porqué del cambio. Para que el conjunto simbólico que formaba la procesión tuviese sentido, el recorrido había de ser siempre igual y aunque la ruta sur-norte cubriese las mismas calles, fue descartada al año siguiente. Tradición e identidad van unidas en la aprehensión simbólica del territorio y, una vez consolidadas, las rutas se alteran lo menos posible.

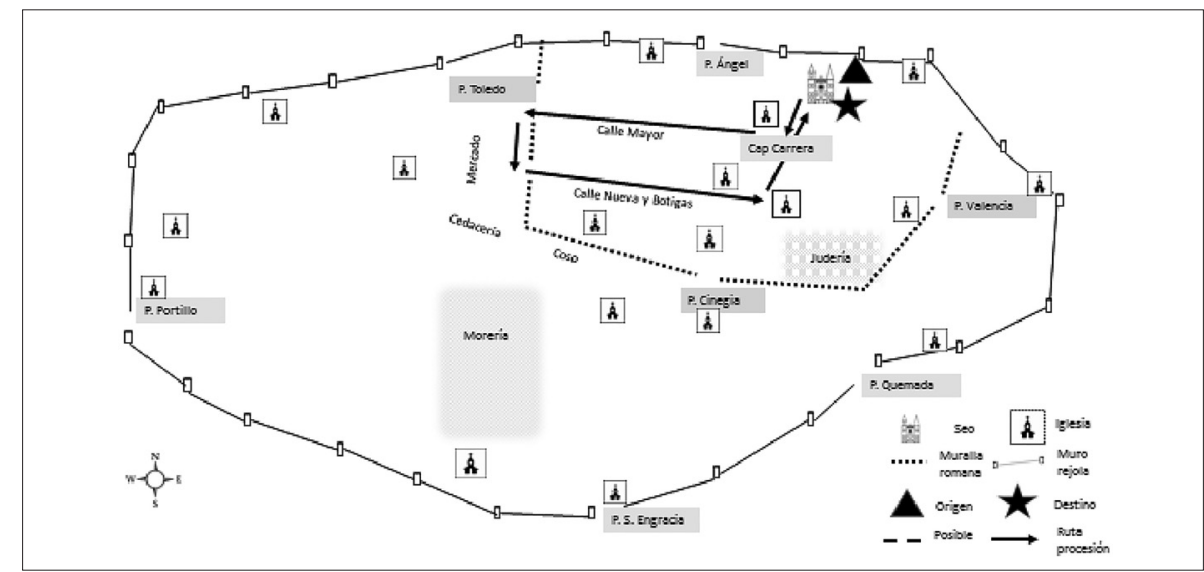

Figura 9. Recorrido circular habitual N-S de la procesión del Corpus. (Elaboración propia).

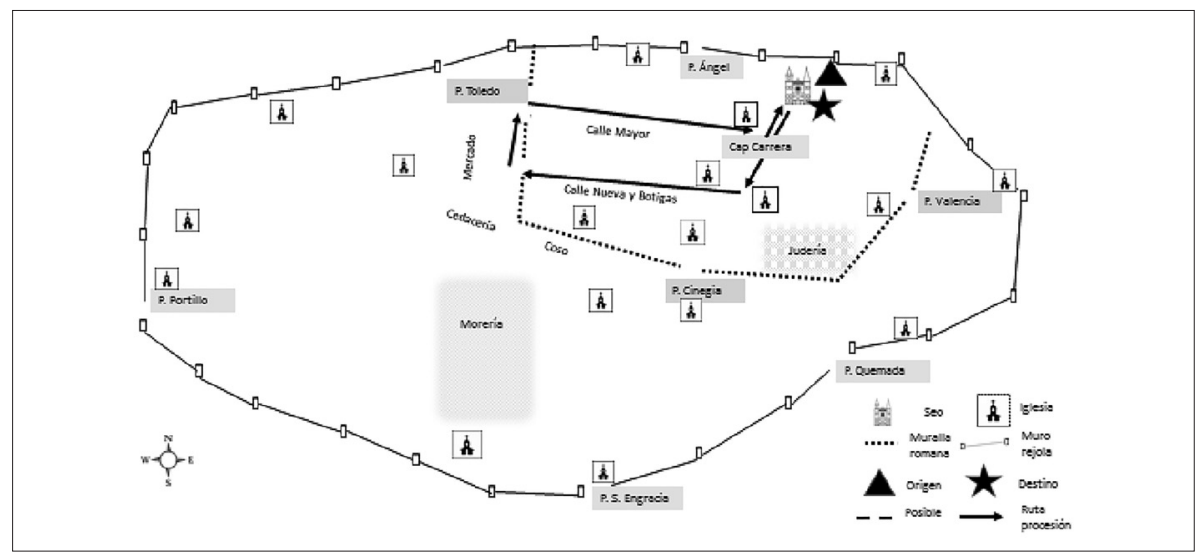

Figura 10. Recorrido circular excepcional (S-N) de la procesión de Corpus en 1454.

(Elaboración propia). 
Un recorrido central permitía un desfile visualmente potente y ordenado de todos los estamentos de la sociedad: autoridades religiosas, ediles y oficiales municipales, cofradías y vecinos. Sin un destino determinado, lo fundamental en estas rutas fue poder recorrer las zonas principales de la ciudad incluido el Mercado. En el mundo urbano de la baja Edad Media plazas y mercados eran enclaves principales de la vida social y símbolos del pleno apogeo de la ciudad frente al campo. Espacios polivalentes que actuaban como centros del comercio, escenarios de las acciones judiciales, corazones del poder político, núcleos informativos, lugares de ocio común y de celebración. En algunas ciudades se potenciaba una de las plazas para que cumpla este papel en exclusiva. En el caso de Zaragoza, este centro vital parece estar compartido entre la plaza de la Diputación (sede del poder político y eclesiástico) y el Mercado, situado al otro lado de la puerta de Toledo y centro de la vida económica ciudadana. Con ocasión de la celebración de procesiones y fiestas, el Mercado cedía su espacio al rito religioso, a los entremeses, corridas de toros y bailes:

\section{[...] cras domingo empres de comer se correran toros en el Mercado. ${ }^{68}$ \\ [...] por veneracion de la dita fiesta se fagan en la dicha ciudat carros e en- tremeses. Los quales por no dar empacho a la dita procesion solament se ffaran en el Mercado de la dita ciudat e apres de comer. ${ }^{69}$}

\subsubsection{Procesiones de ida y vuelta}

La mayoría de las procesiones tuvieron como destino una de las iglesias de la ciudad, incluida la propia catedral, donde se celebraba el oficio y sermón de la festividad o rogativa. Durante las procesiones, el espacio quedaba delimitado por su recorrido de forma que podemos hablar de procesiones tras la muralla romana, tras el muro de rejola y extramuros. Casi siempre, estos tipos dependen de la topografía religiosa (localización de la iglesia) de forma que las procesiones únicamente salieron extramuros si las iglesias a las que se encaminaban estaban situadas más allá del muro de rejola, como las de los conventos de Altabás y Jesús. No debemos perder de vista la importancia simbólica de la muralla. La muralla crea la ciudad, la separa del campo formando una unidad territorial bien delimitada, dibuja un círculo protector del espacio y es elemento identitario de la comunidad urbana. 
No son muy frecuentes las procesiones que permanecen limitadas por la muralla romana. Sin embargo, en ocasiones, el mismo destino cuenta con dos rutas, una corta tras el muro romano y otra larga fuera de él. Es el caso de las procesiones a Santa María la Mayor (figura 11), que en los últimos años del período y, en especial, con motivo de la acción de gracias por los éxitos en la campaña de Granada parecen preferir la ruta larga, más visible gracias a su paso por el Mercado. Todo lo contrario que el trayecto interior, más piadoso e intimista, de 1474 a la Seo con motivo de una rogativa por la salud de Juan II, que evita los lugares más transitados de la ciudad (figura 12).

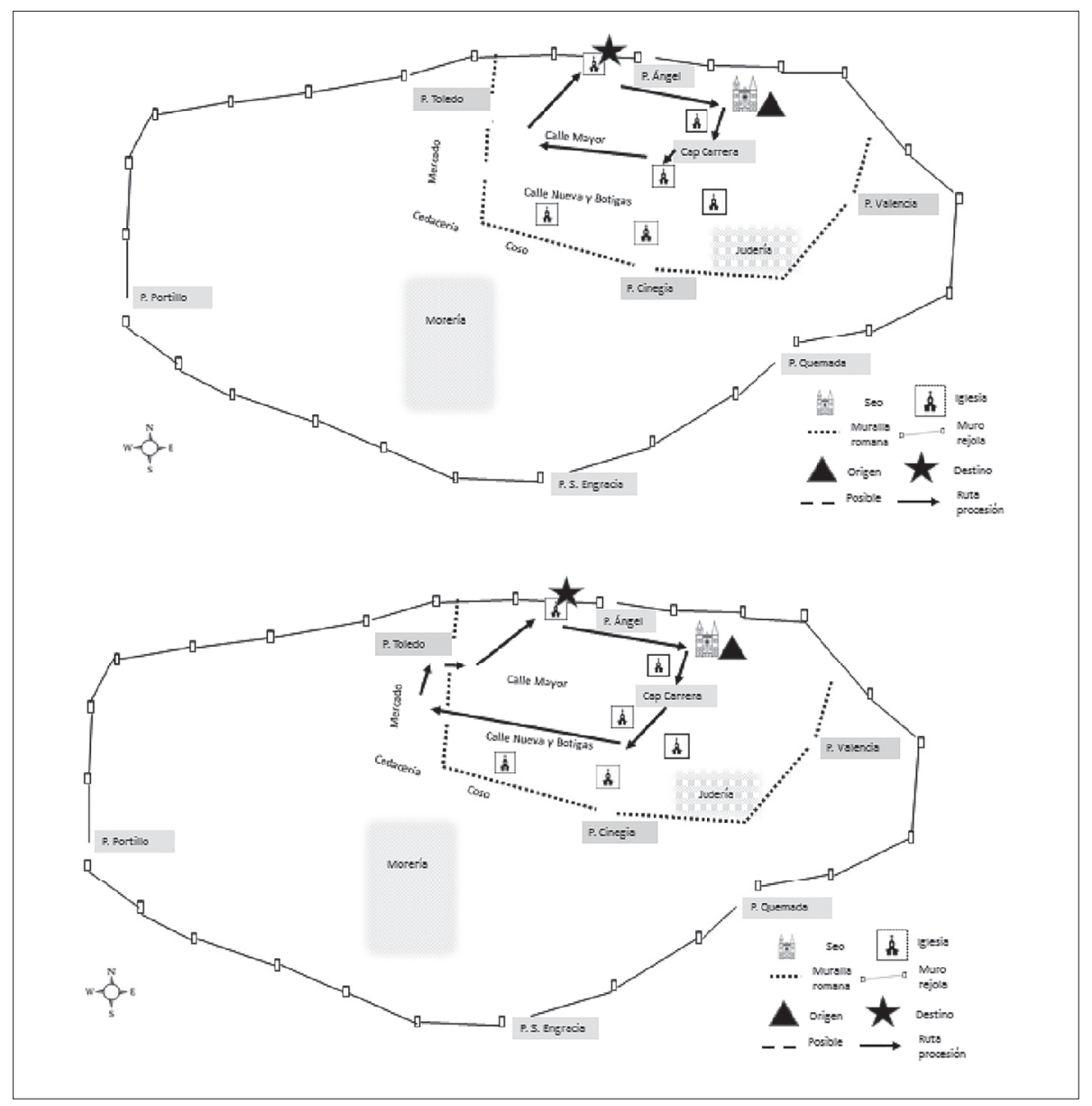

Figura 11. Rutas lineales larga y corta en las procesiones a Santa María la Mayor. (Elaboración propia). 
Salir de este primer círculo protector supone atravesar una de las puertas, edificios emblemáticos que cierran el paso a la ciudad de cualquier elemento externo a la vez que permiten la comunicación controlada con el exterior. Las salidas en función de la dirección son las siguientes:

a) La puerta de Toledo, en el extremo oeste de la calle Mayor, que conectaba con el Mercado y el barrio de San Pablo (desde el siglo XIII, zona de ensanche muy amplia y poblada, cotizada por notarios y mercaderes). Desde 1440 en sus torres se ubicaron las cárceles reales. Fue la salida natural de las procesiones con dirección oeste, que habitualmente retornaron por la misma puerta o por el trenque de la calle Nueva (figuras 13 y 14). También salían por esta misma puerta las procesiones en dirección sur que vuelven a entrar por la puerta Cinegia (figura 15). Mucho menos frecuentes son las que utilizan para salir en las direcciones anteriores el trenque de la calle Nueva. De forma excepcional se hace en 1500 con destino al monasterio de Predicadores (figura 16) y en las procesiones a Santa María del Temple (figura 17), que alargan de esta forma la primera parte del recorrido hasta llegar a su destino.

b) La puerta Cinegia permitía dar salida a las procesiones que se encaminaban a San Miguel (figura 18) o Santa Catalina al sudeste (figura 19) y que retornaban por la puerta de Valencia, haciendo así el recorrido más largo que si volvieran sobre sus pasos.

c) La puerta de Valencia da salida a las procesiones con dirección noreste (figura 20), que vuelven por la misma puerta.

d) La puerta del Ángel, al norte. Es la única que permite salir totalmente fuera de los muros (figura 21).

En todos los recorridos descritos, se está hablando de procesiones por las calles de la ciudad, pero en algunas ocasiones las cridas mencionan desfiles procesionales en el interior de las iglesias, aunque la información que proporcionan es muy escasa y no permite un análisis en profundidad. 


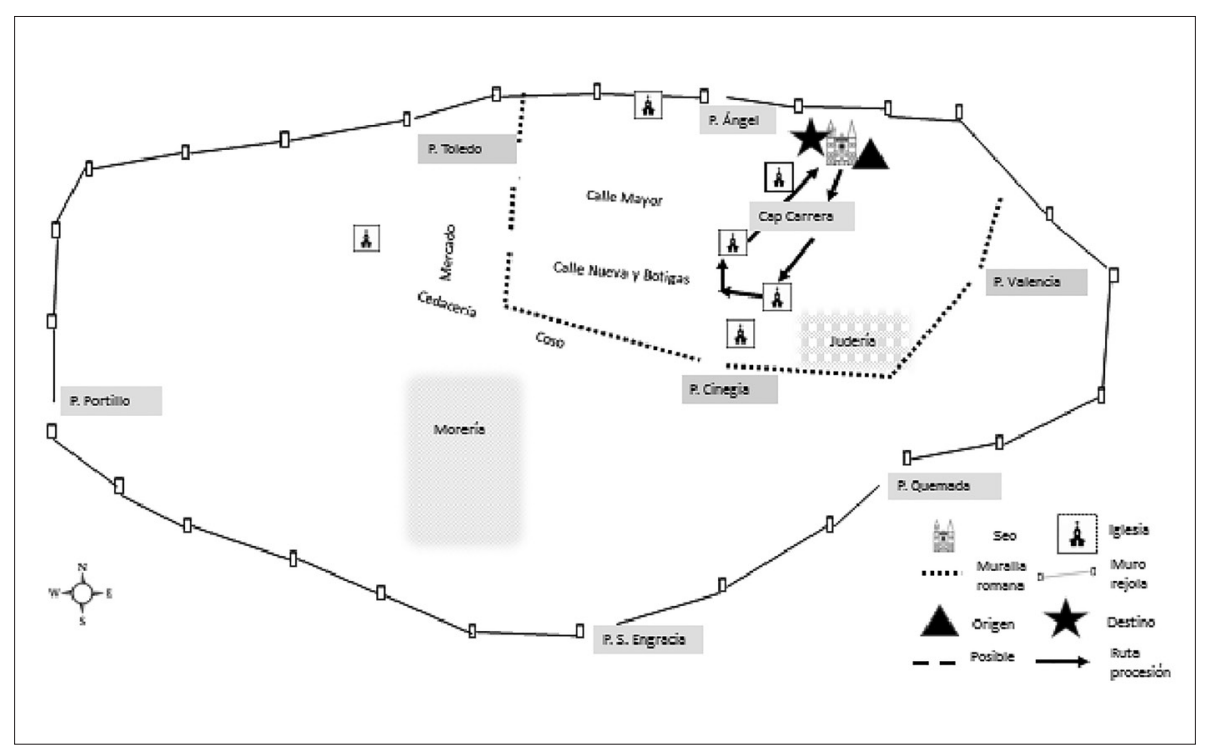

Figura 12. Procesión a la Seo en 1474. Rogativa por la salud del rey Juan II. (Elaboración propia).

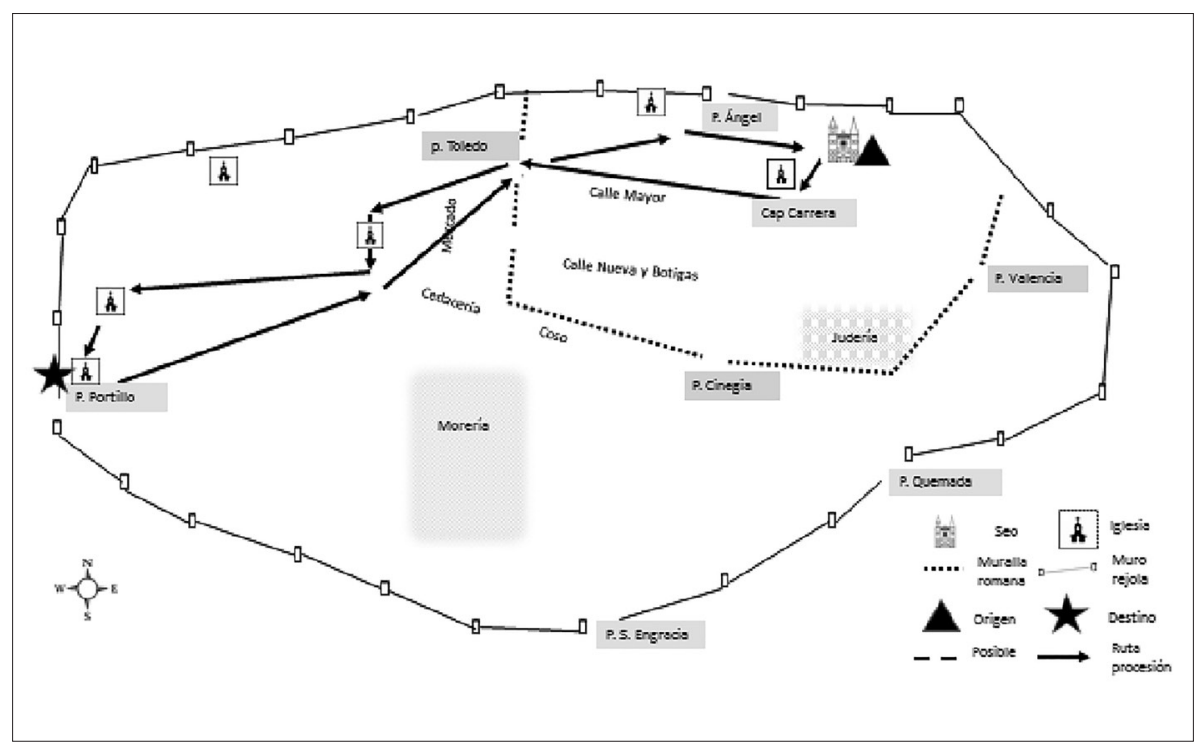

Figura 13. Procesión a la iglesia de San Martín del Portillo. (Elaboración propia). 


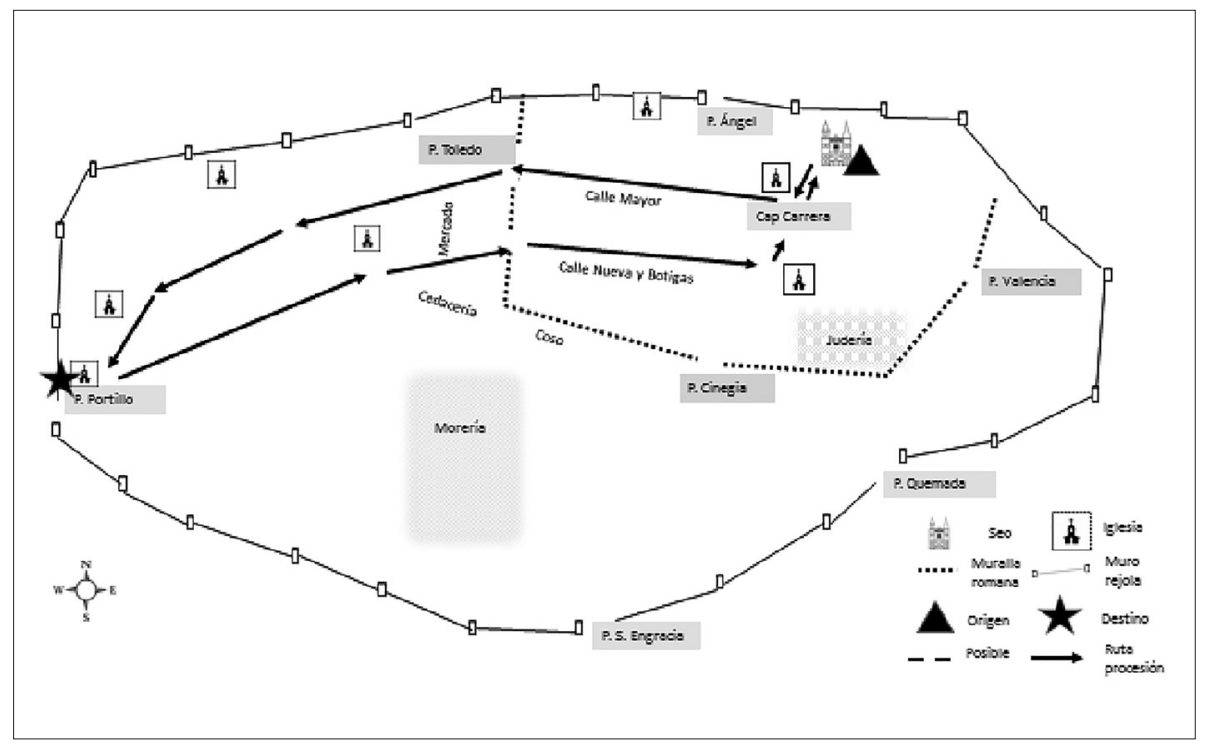

Figura 14. Procesión a la iglesia de San Martín del Portillo. (Elaboración propia).

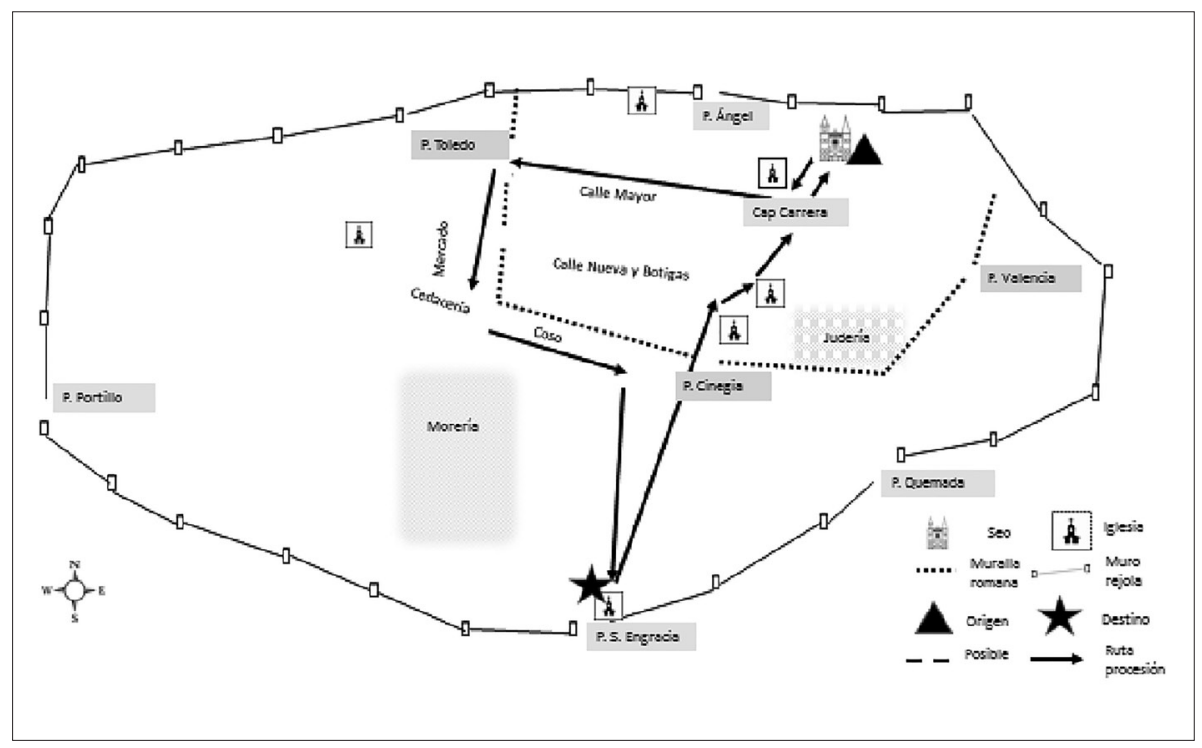

Figura 15. Procesión a la iglesia de Santa Engracia (Elaboración propia). 


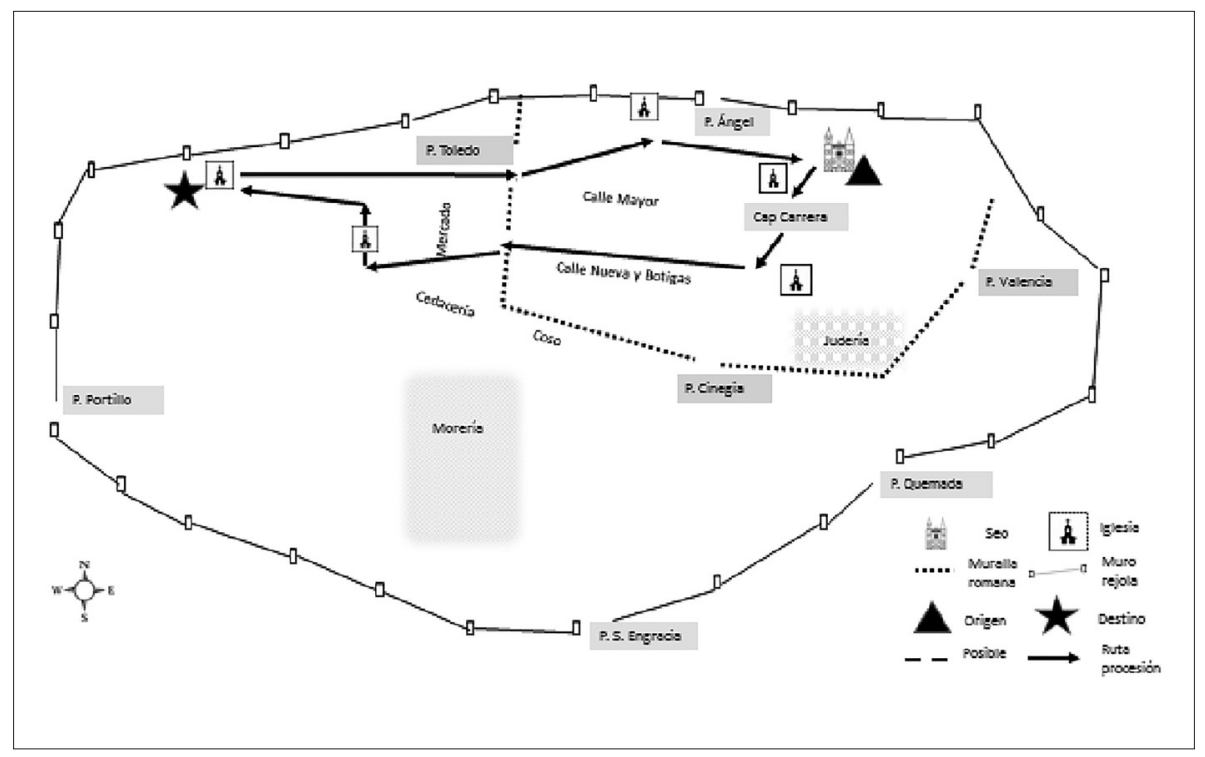

Figura 16. Procesión al monasterio de Predicadores en 1500. (Elaboración propia).

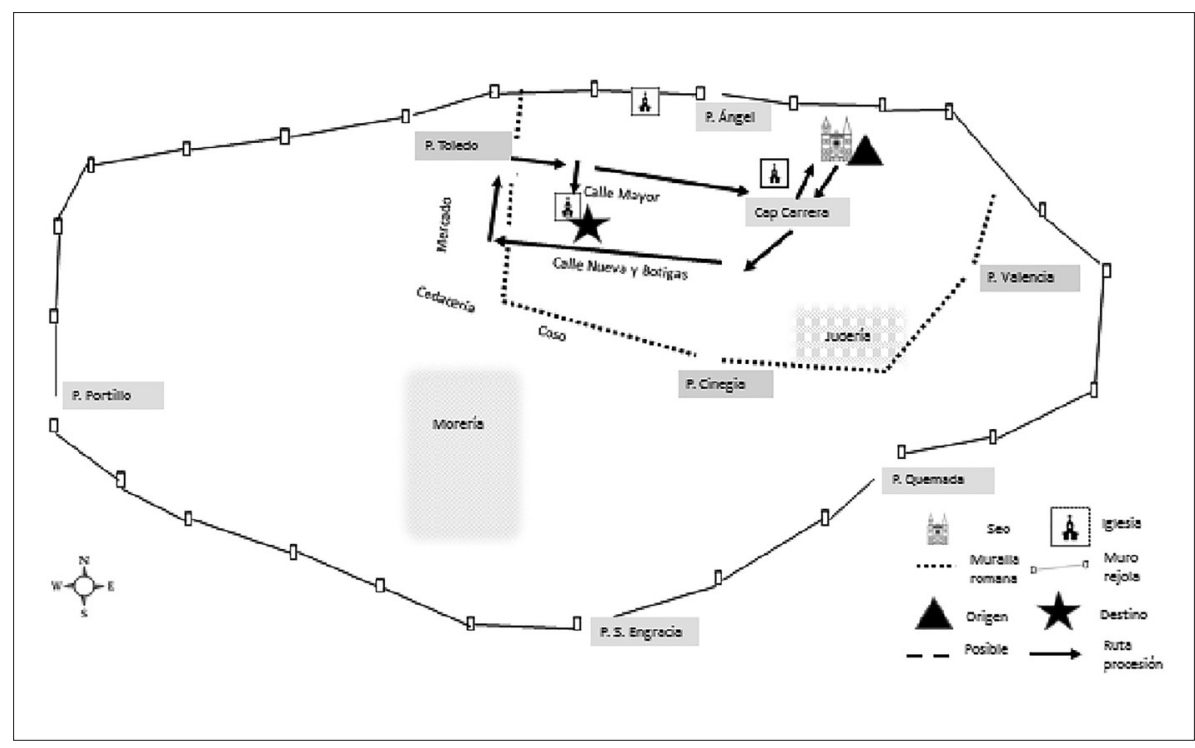

Figura 17. Procesión a la iglesia de Santa María del Temple. (Elaboración propia). 


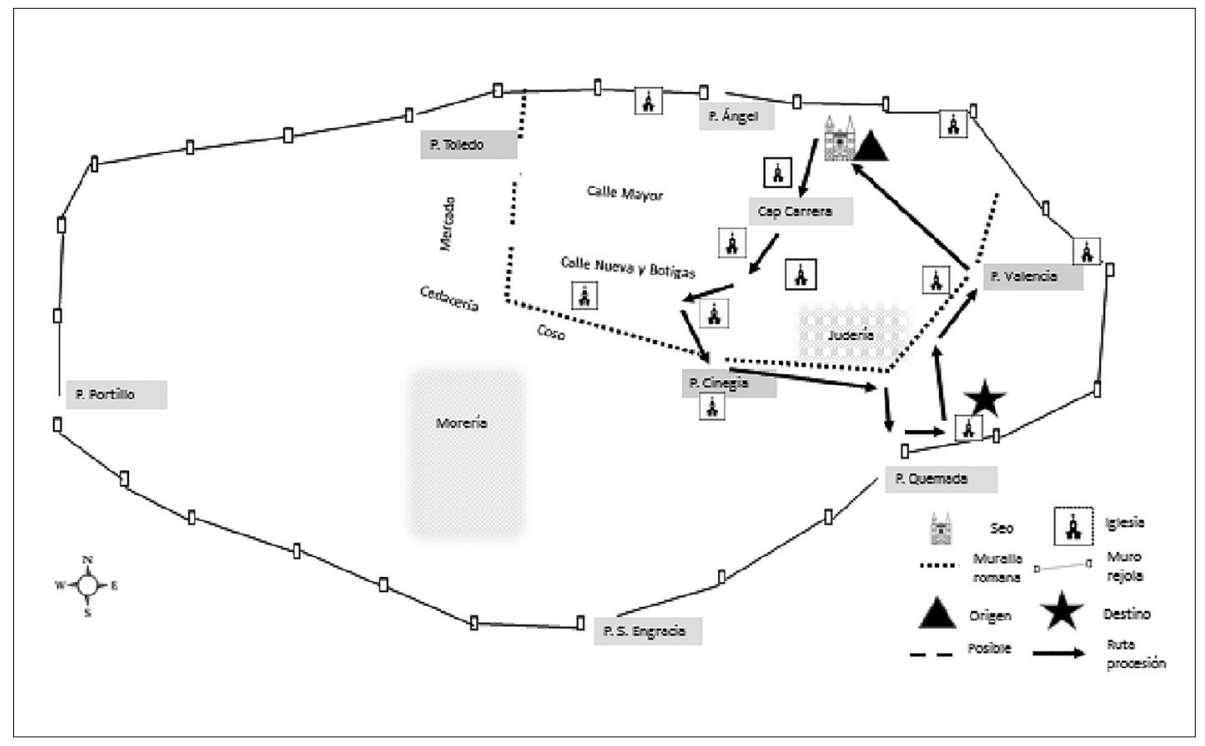

Figura 18. Procesión a la iglesia de San Miguel de los Navarros. (Elaboración propia).

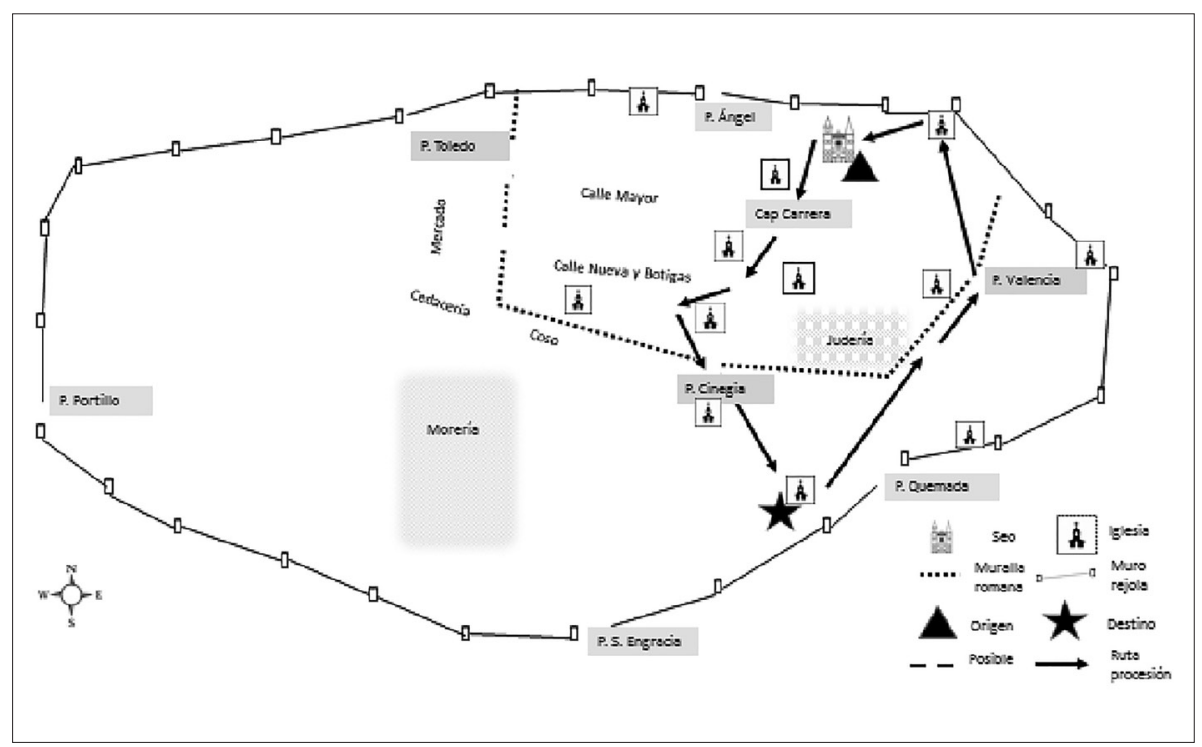

Figura 19. Procesión al monasterio de Santa Catalina. (Elaboración propia). 


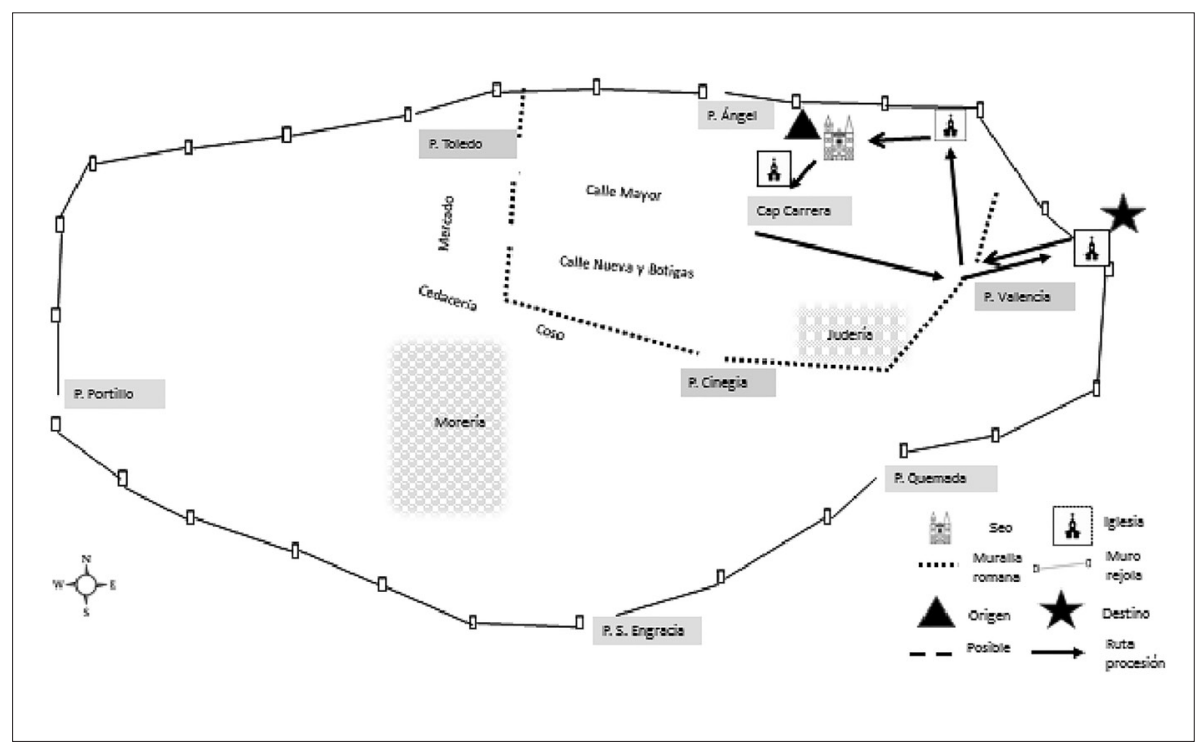

Figura 20. Procesión al monasterio de San Agustín. (Elaboración propia).

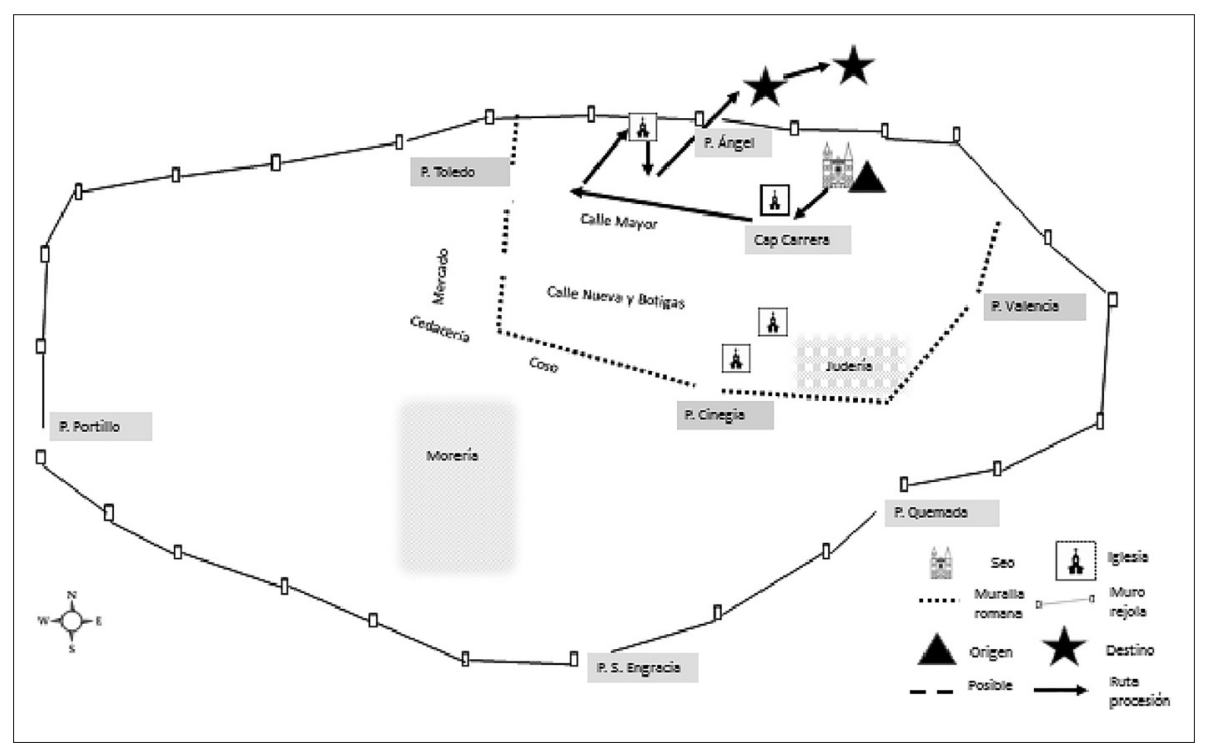

Figura 21. Procesiones a los conventos de Altabás y Jesús. (Elaboración propia). 


\subsection{El control del Concejo}

El éxito de este complejo sistema procesional dependía en buena parte de la habilidad de las autoridades municipales para gestionar estos acontecimientos. Había que conseguir la participación de todos, evitar conflictos, controlar el espacio y vigilar el comportamiento de las minorías religiosas.

La propia acción de pregonar la noticia por distintos puntos de la ciudad supone ya, en sí misma, un conocimiento y control del espacio urbano que era jerarquizado, probablemente en función de su importancia simbólica, demográfica, económica o social. Este control era fundamental para garantizar que nadie pudiese esgrimir como excusa una deficiencia en la trasmisión de la información:

Et por tal que alguno de lo sobredito ignorancia no pueda allegar los ditos jurados mandan fazer la present crida por los lugares acostumbrados de la dita ciudat. ${ }^{70}$

Por la devoción debida, pero también con objeto de que la fiesta luciera en todo su esplendor, casi la totalidad de los pregones exigen que los vecinos limpiasen, barriesen y regasen las calles si la procesión pasaba por delante de sus casas. A veces se pedía también que retirasen los tablados y carros que pudieran entorpecer la circulación y, en las fiestas más solemnes como el Corpus Christi, que se adornasen las ventanas con velas y paños. En cuanto a la limpieza de zonas comunes, se ordenaba que las calles se cubriesen de juncos y paja para evitar el contacto del Sacramento con el barro y el polvo.

Las minorías religiosas se hacen más visibles en los pregones a medida que pasa el tiempo. Si bien parece que las procesiones al monasterio del Carmen (figura 22) pudieron atravesar la morería (en 1450 se dice que la procesión irá por la Cedaçeria et por la Fferreria et Moreria al Carmen ${ }^{71}$ ), todas las que se encaminaron al este o sudeste (rutas 7 y 10) evitaron pasar por la judería, ya que el contacto podría contaminar el ritual. Pero los imponderables ocurrían, así que era mejor preverlos. Por eso, el Concejo mandaba que durante las procesiones, en especial la del Corpus Christi, «todas las casas de los jodios

e moros que sallen a carreras de cristianos hayan a estar cerradas $»^{72}$ que ni judíos ni moros se atreviesen a mirar la procesión desde las ventanas y que

70 PRE-02, cuadernillo 1, f. 24 r.

71 PRE-02, cuadernillo 1, f. 17v.

72 PRE-02, cuadernillo 12, f. 14 v. 
aquél que se encontrase en la calle en el momento de pasar la procesión sea tenido genollarse. ${ }^{73}$ Se prohibió también que durante las procesiones los judíos trabajasen en lugares donde pudieran ser vistos por cristianos. Se trataba, por tanto, de evitar agravios que pudieran alterar el orden público.

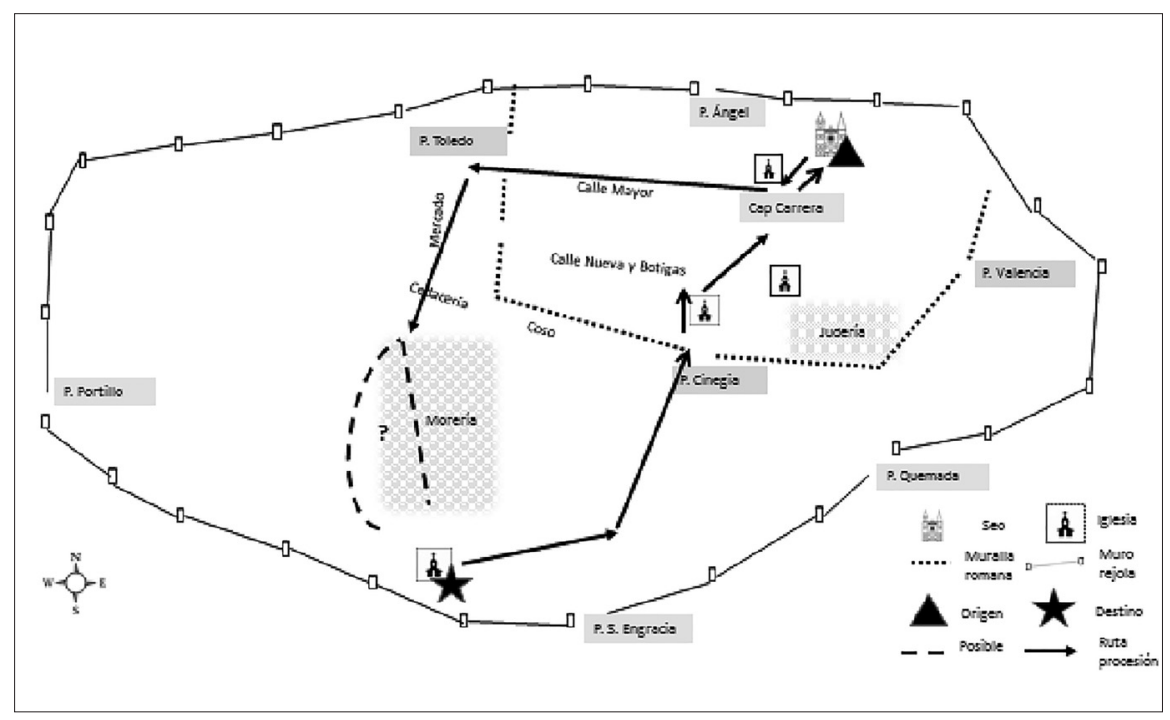

Figura 22. Procesión al monasterio del Carmen. (Elaboración propia).

Que la ciudad mantenga la paz y el orden fue otra de las prioridades de las autoridades. Por lo que respecta a las armas, los jurados ordenaron que

[...] persona alguna no sea osada levar spada ni armas algunas por la ciudat dig pena de perder aquellas certificando a qualesquiere personas que levaran aquellas les seran tiradas et seran perdidas sin remision alguna de las cobrar. $^{74}$

\section{Y para evitar altercados y no estorbar a la propia procesión se prohibió}

[...] andar a cavallo por do la dita procession ira fasta que la dita procession sia passada e tornada a la Seu ius pena de perder la cavalgadura aplicadera a la ciudat, ni star acavallo en la plaça de la dita Seu mientre se faran los ditos entremeses ius la dita pena. ${ }^{75}$

73 PRE-02, cuadernillo 13, f. 21 r. Genollarse o arrodillarse, del latín genu, rodilla.

74 PRE-04, f. 24 v.

75 PRE-02, cuadernillo 11, ff. 17v. y $18 \mathrm{r}$. 
Tanto el ambiente festivo como la sensación de identidad común que propicia la celebración de ritos y celebraciones colectivas pueden provocar excesos no deseados contra las minorías, excluidas por su otredad. Era necesario mantener el control del orden en las calles y en la celebración del Corpus de 1479 los jurados ordenaron que

\begin{abstract}
[...] todas e qualesquiere personas de qualquiere ley, stado o condicion sian que ninguno sea osado coser o lligar cohetes en las ropas de persona alguna nin de judio o moro nin tirarles a los dichos judios capirotes nin fazerles mal, danyo o injuria dius pena de cinquenta açotes et estar cient dias en la carcel sin remission alguna. ${ }^{76}$
\end{abstract}

Para garantizar el cumplimiento de las normas municipales se impusieron multas (la mayoría de las veces) u otro tipo de penas. Las multas oscilaron entre los 5 y los 100 sueldos dependiendo de dos factores principales: la solemnidad del acontecimiento y la pertenencia del sancionado a una minoría religiosa. Habitualmente se sancionó con entre 5 y 10 sueldos la no asistencia a los actos. Hay que tener en cuenta que muchas de las procesiones llevaban aparejada la interrupción de las actividades económicas (como la apertura de comercios) hasta la finalización de las mismas y todas ellas la exigencia de que al menos un miembro de cada casa abandonara su rutina diaria para acompañar la comitiva. Esta alteración del ritmo diario no siempre fue bienvenida por los vecinos. Sanciones similares se aplicaron por no cumplir las ordenanzas de limpieza, trabajar durante la fiesta o no llevar cirios en la procesión. En algunas zonas especiales, como la Cedacería, o si las cabezas de los santos debían pasar por el recorrido, las multas por limpieza aumentaban normalmente hasta los 20 sueldos. En ocasiones excepcionales, la multa por limpieza llegó hasta los 50 (e.g. procesión del Corpus Christi de 1500) ó 100 sueldos (procesión de acción de gracias por la recuperación de Otranto en 1483). Llaman poderosamente la atención las multas a las minorías religiosas, que van aumentando con el paso del tiempo. En ocasiones, estas sanciones económicas evolucionaron hasta convertirse en penas físicas o de cárcel (en los primeros años del periodo se multa con 30 sueldos a los judíos que no se arrodillen al paso del Sacramento mientras que, en los años finales, la pena será de azotes). Se multaba, por ejemplo, con 60 sueldos a los judíos o moros que trabajasen durante el Corpus y a los que fueran hallados en las ventanas mirando la procesión. Las autoridades aplicaron también confisca- 
ciones, como la pérdida del caballo o de las armas a quienes desoyeran la prohibición de llevarlas.

Las sanciones físicas y las penas de cárcel se reservaron para las minorías religiosas o las trasgresiones blasfemas. Así, ir disfrazado con hábitos de fraile o capellán solía llevar aparejada pena de 8 días de cárcel o de azotes y no arrodillarse al paso del Corpus - en este punto los pregones suelen hacer mención explícita a los judíos o moros - también derivó en pena de azotes.

En su mayor parte, el importe de las multas, tanto en dinero como en especie, fue a parar al común de la ciudad, aunque en ocasiones se dividía en tres partes. Si éste era el caso, un tercio solía corresponder al acusador, otro tercio al común de la ciudad y el último tercio a la iglesia de destino o a diferentes actuaciones del Ayuntamiento. En función de los momentos vemos como las prioridades variaron: las obras del puente (en 1455) o el Hospital de Gracia (desde 1478), cuyo control financiero dependía del Concejo de Zaragoza. En casos excepcionales, un tercio de la multa se destinó al monarca, como se estipula en el pregón del Corpus Christi de 1480 (atendiendo a la fecha, probablemente con objeto de financiar los gastos militares de la Corona).

\section{Conclusión}

Los Libros de Pregones han resultado ser una fuente documental de indudable interés para el estudio de las procesiones religiosas en la Zaragoza de la segunda mitad del siglo XV. Una lectura detallada permite dibujar un sistema procesional ordinario - con rutas regulares y basado en el calendario litúrgico y devocional cristiano - al margen del cual, y cuando las circunstancias lo requirieron, se organizaban todo tipo de rogativas, acciones de gracias y celebraciones. Nuestra fuente ha desvelado las devociones más comunes, algunas de ellas de carácter cristiano general (como la devoción al Corpus Christi o algunas advocaciones marianas) y otras específicas de la Corona de Aragón o la ciudad de Zaragoza (como el Ángel Custodio o los santos Mártires). Analizando las procesiones extraordinarias es posible deducir cuáles fueron las preocupaciones del día a día de la ciudad y cuáles estaban relacionadas con el papel de Zaragoza como cabeza del reino.

Algunas procesiones parecen surgir de la iniciativa pastoral de las congregaciones religiosas (en especial franciscanos y dominicos), interesadas en impulsar la devoción por figuras venerables de su orden (san Vicente Ferrer, san- 
ta Catalina de Siena, san Bernardino, etc.) o afirmar su posición con respecto a ciertas cuestiones dogmáticas como la Inmaculada Concepción de la Virgen. De forma más o menos directa, la autoridad real se halla detrás de un segundo grupo de procesiones, especialmente desde finales del reinado de Juan II. Éstas estuvieron, en parte, motivadas por circunstancias excepcionales - principalmente las guerras y la salud del rey- $\mathrm{y}$, en parte, por la condición de la ciudad como capital de Aragón y por su importancia simbólica para la Corona. Las autoridades municipales se encontraron detrás de muchas de las procesiones extraordinarias. En momentos de crisis meteorológica o de producción, el Concejo hizo suyos los desvelos y preocupaciones de los vecinos recurriendo al poder divino. No fue una implicación del todo desinteresada puesto que una de las funciones de los munícipes consistía en mantener el orden público.

El Concejo de la ciudad fue esencial en la formación de la devoción a los santos locales. El orgullo que la ciudad sentía por ellos, en especial por sus mártires, se hizo patente en algunas de las cridas y la importancia que para Zaragoza tuvo el templo de Santa Engracia queda reflejada en las tres procesiones anuales de carácter ordinario. Independientemente del tipo de procesión, las autoridades locales jugaron siempre un papel fundamental en la organización, desarrollo y vigilancia de la misma. En este sentido, podría decirse que el Concejo controlaba el espacio urbano tanto a nivel físico como simbólico, creando unas rutas procesionales que cumplieron una función integradora de la comunidad cívica y cristiana a la par que excluyente de las minorías religiosas.

Finalmente, este estudio pretendía determinar si era posible aplicar el concepto de religión cívica para el caso de la Zaragoza de la segunda mitad del siglo XV. Acabamos de mencionar el papel fundamental que jugaron las autoridades municipales en la organización de las procesiones religiosas. Los pregones presentan, además, a un Concejo implicado en la gestión financiera de instituciones de caridad, como el Hospital de Nuestra Señora de Gracia, al que fueron destinadas muchas de las multas impuestas por contravenir sus disposiciones.

Aunque no parece que la Iglesia llegara a perder el control de las preciadas reliquias de los santos locales, custodiadas en los diferentes templos de la ciudad, su utilización en rogativas de iniciativa municipal o en procesiones relacionadas con el poder real parece indicar cierto poder de decisión sobre su participación en las mismas. Por otra parte, el complejo sistema procesional descrito, tanto en sus tiempos como en sus espacios, contribuyó, por un lado, 
a hacer visibles a las autoridades municipales y a crear un vínculo entre ellas y la divinidad y, por otro, a reforzar el sentimiento de unidad e identidad de la propia ciudad. En suma, debemos concluir que las autoridades locales en la Zaragoza de la segunda mitad del siglo xv jugaron un papel determinante en el fenómeno religioso, lo que permite hablar de una religión cívica.

\section{Referencias bibliográficas}

Ainaga, Teresa y Jesús CRiado (2008), «El busto relicario de San Braulio (1456-1461) y la tradición de la venida de la Virgen del Pilar a Zaragoza», Aragón en la Edad Media, 20: 65-84.

BARRAQUÉ, Jean Pierre (2008), «Entre religión real y religión urbana», En la España Medieval, 31: 249-274.

BARRAquÉ, Jean Pierre (2013) «Construire une identité de capitale. Saragosse à la fin du Moyen Age.» En José Antonio Jara Fuente (coord.), Ante su identidad. La ciudad hispánica en la Baja Edad Media. Cuenca, Universidad de Castilla-La Mancha: 59-74.

Bordes, François (2004), «Une perception de l'espace urbain : cortèges officiels et processions générales à Toulouse $\mathrm{du} \mathrm{XIV}^{\mathrm{e}}$ au XVI ${ }^{\mathrm{e}}$ siècle», Mémoires de la société archéologique du midi de la France, 64: 135-153.

Boucheron, Patrick (2013), «Religion civique, religión civile, religión séculière. L'ombre d'un doute», Revue de synthèse, 134/2: 161-183.

Buesa Conde, Domingo (1987), «Manifestaciones de la religiosidad popular en la Zaragoza del siglo xv: las procesiones devocionales, penitenciales y en acción de gracias por la toma de Granada», Aragonia Sacra, 2: 45-58.

Chevalier, Bernard (1995), «La religion civique dans les bonnes villes : sa portée et ses limites. Le cas de Tours.» En La religion civique à l'époque médiévale et moderne (chrétienté et islam). Actes du colloque organisé par le centre de recherche «Histoire sociale et culturelle de 1〉Occident. XII ${ }^{e}$-XVIII siècle» de l'Université de Paris X-Nanterre et l'Institut universitaire de France. Rome, École Française de Rome: 337-349.

Chiffoleau, Jacques (1994), «Analyse d'un rituel flamboyant: Paris, mai-août 1412.» En Jacques Chiffoleau, Lauro Martines y Agostino Paravicini (dirs.), Riti e rituali nelle società medievali. Spoleto, Centro italiano di studi sull'Alto Medioevo: 215245.

Cía Blasco, Javier (2001-2002), «Precedentes y orígenes del Monasterio Jerónimo de Santa Engracia de Zaragoza», Revista de Historia Jerónimo Zurita, 76-77: 7- 90. 
Criado Mainar, Jesús (2000), «La tradición medieval en los bustos relicarios zaragozanos al filo de 1500. Las esculturas de plata de San Gregorio Ostiense y Santa Isabel de Bretaña», Aragón en la Edad Media, 16: 215-236.

Criado Mainar, Jesús (2014), «Los bustos relicarios femeninos en Aragón, 1406-

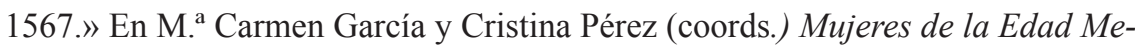
dia: actividades políticas, socioeconómicas y culturales. Zaragoza, Institución Fernando el Católico: 341-368.

FAlCón PÉrez, M. ${ }^{a}$ Isabel (1980), «Sanidad y Beneficencia en Zaragoza en el siglo XV», Aragón en la Edad Media, 3: 183-226.

FalCón Pérez, M. ${ }^{a}$ Isabel (1982), «La festividad del Corpus Christi en los pueblos de Aragón en la Edad Media.» En Estado actual de los estudios sobre Aragón. Actas de las quintas jornadas. Zaragoza, Instituto de Ciencias de la Educación: 625-632.

FALCón Pérez, M. ${ }^{a}$ Isabel (1982), «La procesión del Corpus Christi en Zaragoza en el siglo XV.» En Estado actual de los estudios sobre Aragón. Actas de las quintas jornadas. Zaragoza, Instituto de Ciencias de la Educación: 633-642.

FALCón PÉREZ, M. a Isabel (1997), «Religiosidad popular en Zaragoza en el siglo XV.» En Religiosidad popular en España. Actas del Simposium. Vol. I. Religiosidad, devociones, culto mariano y a los santos, mentalidad... El Escorial, Real Centro Universitario Escorial-M. ${ }^{\text {a }}$ Cristina: 877-897.

FALCón PÉRez, M. ${ }^{a}$ Isabel (1998), La sociedad aragonesa medieval. Zaragoza, Librería General.

FALCón PÉRez, M. ${ }^{a}$ Isabel (2010), Ordinaciones reales otorgadas a la ciudad de Zaragoza en el siglo XV. De Fernando I a Fernando II. Zaragoza, Institución Fernando el Católico.

FALCón PÉRez, M. ${ }^{a}$ Isabel (2011a), Zaragoza en el siglo XV. Morfología urbana, huertas y término municipal. Zaragoza, Institución Fernando el Católico.

FALCón PÉREZ, M. ${ }^{a}$ Isabel (2011b), «Devociones populares, procesiones e imágenes de santos en la Zaragoza del siglo XV», Aragonia Sacra, 21: 171-200.

FatÁs CABeza, Guillermo (2009), Del patrono de la universidad de Zaragoza y de cómo fue destruida en 1809. Zaragoza, Prensas universitarias de Zaragoza.

García Herrero, M. ${ }^{a}$ Carmen y M. ${ }^{a}$ Jesús Torreblanca Gaspar (1993), «San Miguel y la plaga de langosta (claves para la interpretación del voto taustano de 1421)» Aragón en la Edad Media, 10-11: 281-306.

Geertz, Clifford (2003), La interpretación de las culturas. Barcelona, Gedisa.

Kantorowicz, Ernst (1957), The King's Two Bodies. Princeton, Princeton University Press.

Kuchenbuch, Ludolf, Joseph Morsel y Dieter Scheler, (2010), «La construction processionnelle de l'espace communautaire.» En Didier Boisseuil, Pierre Chastang, 
Laurent Feller y Joseph Morsel (coords.) Écritures de l〉espace social. Mélanges d`histoire médiévale offerts à Monique Bourin. Paris, Publications de la Sorbonne: 139-182.

Lafuente Gómez, Mario (2008), «Devoción y patronazgo en torno al combate en la Corona de Aragón: las conmemoraciones a San Jorge de 1356», Aragón en la Edad Media, 20 (Homenaje a la profesora María Desamparados Cabanes Pecourt): 427-444.

Lafuente Gómez, Mario (2016), «Las murallas de Zaragoza en la Edad Media.» En Recintos amurallados. Actas de las VII Jornadas de Castellología Aragonesa. Zaragoza, Asociación para la Recuperación de los Castillos en Aragón (ARCA)-Iniciativa Cultural Barbacana: 231-266.

Ledesma Rubio, M. ${ }^{a}$ Luisa e Isabel Falcón Pérez (1977), Zaragoza en la baja Edad Media. Zaragoza, Librería General.

Leone, Massimo (2014), «Transcendence and Transgressions in Religious Procession», Signs and Society, 2/2: 314-348.

Llompart, Gabriel (1967), «La fiesta del Corpus y representaciones religiosas en Zaragoza y Mallorca (siglos XIV-XV)», Analecta Sacra Tarraconensia, 42: 181-209. Disponible en red.

Llompart, Gabriel (1971), «El Ángel Custodio en los Reinos de la Corona de Aragón», Boletín de la Cámara oficial de Comercio, Industria y Navegación de Palma de Mallorca, 673: 147-188.

Llompart, Gabriel (1988), «El Ángel Custodio en la Corona de Aragón en la Baja Edad Media.» En Fiestas y Liturgia. Actas del coloquio celebrado en la casa de Vélazquez-Fêtes et Liturgie. Actes du colloque tenu à la Casa de Velázquez 12/14XII-1985. Madrid, Casa de Velázquez y Universidad Complutense: 249-270.

Mateos Royo, José Antonio (1996-1997), «Teatro religioso y configuración escénica: Los entremeses del Corpus en Zaragoza (1480)», Archivo de filología aragonesa, 52-53: 103-116.

Mateos Royo, José Antonio (2001), «Municipio y espectáculo teatral: los entremeses de la ciudad de Zaragoza (1440-1540)», Archivo de filología aragonesa, 57-58: 11-48.

Muñoz Salillas, Juan (1944), «Privilegios a favor del Hospital de Nuestra Señora de Gracia de Zaragoza», Anuario de Derecho Aragonés, 1: 143-165.

NARBona VizCAíno, Rafael (1996) «Héroes, tumbas y santos: la conquista en las devociones de Valencia medieval», Saitabi, 46: 293-320.

NARBona VizCAíno, Rafael (1999), «Apreciaciones históricas e historiográficas en torno a la fiesta del Corpus Christi de Valencia», Revista d'historia medieval, 10: 371-382. 
Narbona Vizcaíno, Rafael (2004), «Cortejos ceremoniales, funciones religiosas y simbolismos políticos en las ciudades medievales», en Juan Antonio Barrio (coord.) Los cimientos del Estado en la Edad Media: cancillerías, notariado y privilegios reales en la construcción del Estado en la Edad Media. Alicante, Marfil: 233-248.

QuiÑONES, Juan de (1620), Tratado de las langostas mvy vtil y necesario en que se tratan cosas de prouecho y curiosidad para todos los que profesan letras diuinas y humanas, y las mayores ciencias. Madrid, Luis Sánchez impresor. Disponible en red.

SANMARTín ARCe, Ricardo (1988), «Fiestas y liturgia: procesión, historia e identidad.» En Fiestas y Liturgia. Actas del coloquio celebrado en la casa de Vélaquez- Fêtes et Liturgie. Actes du colloque tenu à la Casa de Velázquez 12/14-XII-1985. Madrid, Casa de Velázquez y Universidad Complutense: 153-168.

SAN Vicente Pino, Ángel (1988), Instrumentos para una historia social y económica del trabajo en Zaragoza en los siglos XV a XVIII. Tomo I. Zaragoza, Real Sociedad Económica Aragonesa de Amigos del País.

Solórzano Telechea, Jesús Ángel (2015), «La identidad urbana y la historia social y política en el mundo urbano español y portugués en la Baja Edad Media», Studia histórica. Historia medieval, 33: 327-341.

Tello Hernández, Ester (2013), Aportación al estudio de las cofradías medievales y sus devociones en el reino de Aragón. Zaragoza, Institución Fernando el Católico.

VAUCHEZ, André (1985), La espiritualidad del occidente medieval, Madrid, Cátedra.

VAUCHEZ, André (1995), «Introduction.» En La religión civique à l'époque médiévale et moderne: chrétienté et islam: actes du colloque. Rome, Publications de l'École française de Rome, 213/1: 1-5.

Velasco GonzÁlez, Alberto (2014-2015), «Para que sus deliberaciones y consejos no vayan herrados sino acertados. Gonzalo de la Caballería y el retablo de la capilla del concejo de Zaragoza (1443)», Turiaso, 22: 295-340.

Villagrasa Elías, Raúl (2016), La red de hospitales en el Aragón medieval (ss. XIIXV). Zaragoza, Institución Fernando el Católico. 